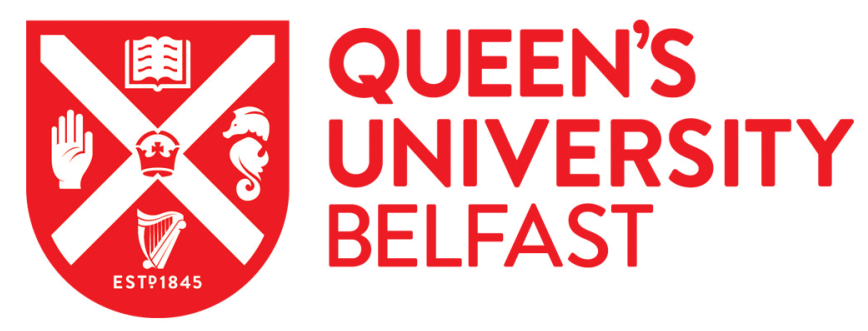

\title{
pH-Responsive benzaldehyde-functionalized PEG-based polymeric nanoparticles for drug delivery: Effect of preparation method on morphology, dye encapsulation and attachment
}

Smyth, P., Gibson, T. J., Irvine, G., Black, G., Lavery, D., Semsarilar, M., Scott, C. J., \& Themistou, E. (2020). $\mathrm{pH}-$ Responsive benzaldehyde-functionalized PEG-based polymeric nanoparticles for drug delivery: Effect of preparation method on morphology, dye encapsulation and attachment. European Polymer Journal, 124, [109471]. https://doi.org/10.1016/j.eurpolymj.2019.109471

\section{Published in:}

European Polymer Journal

\section{Document Version:}

Peer reviewed version

Queen's University Belfast - Research Portal:

Link to publication record in Queen's University Belfast Research Portal

\section{Publisher rights}

Copyright 2020 Elsevier.

This manuscript is distributed under a Creative Commons Attribution-NonCommercial-NoDerivs License

(https://creativecommons.org/licenses/by-nc-nd/4.0/), which permits distribution and reproduction for non-commercial purposes, provided the author and source are cited.

\section{General rights}

Copyright for the publications made accessible via the Queen's University Belfast Research Portal is retained by the author(s) and / or other copyright owners and it is a condition of accessing these publications that users recognise and abide by the legal requirements associated with these rights.

Take down policy

The Research Portal is Queen's institutional repository that provides access to Queen's research output. Every effort has been made to ensure that content in the Research Portal does not infringe any person's rights, or applicable UK laws. If you discover content in the

Research Portal that you believe breaches copyright or violates any law, please contact openaccess@qub.ac.uk. 


\title{
pH-Responsive benzaldehyde-functionalized PEG-based polymeric nanoparticles for drug delivery: effect of preparation method on morphology, dye encapsulation and attachment
}

Peter Smyth, ${ }^{\mathrm{a}}$ Thomas J. Gibson, ${ }^{\mathrm{b}}$ Gavin Irvine, ${ }^{\mathrm{b}}$ Gemma Black, ${ }^{\mathrm{b}}$ Daniel Lavery, ${ }^{\mathrm{b}}$ Mona Semsarilar, ${ }^{c}$ Christopher J. Scott ${ }^{\mathrm{a}}$ and Efrosyni Themistou*b

${ }^{a}$ Centre for Cancer Research \& Cell Biology, Queen's University Belfast, Belfast BT9 7AE, UK

bSchool of Chemistry and Chemical Engineering, Queen's University Belfast, David Keir Building, Belfast BT9 5AG, UK.

'Institut Européen des Membranes, IEM, UMR 5635, Université de Montpellier, ENSCM, CNRS, Montpellier, France

*Corresponding author:

Dr. Efrosyni Themistou; E-mail address: e.themistou@qub.ac.uk

\begin{abstract}
Functionalized, pH-responsive and biocompatible polymeric nanoparticles have attracted the interest of many researches working on novel pharmaceutical formulations. Here, in an effort to develop an efficient drug delivery formulation, all these properties are combined in one polymeric nanoparticle system. More specifically, benzaldehyde-functionalized amphiphilic block copolymers based on PEG-based oligo(ethylene glycol) methacrylate (OEGMA), benzaldehyde-containing para-formyl phenyl methacrylate (pFMA) and pH-responsive 2(diisopropyl)aminoethyl methacrylate (DPA) monomers are readily prepared by reversible addition-fragmentation chain transfer (RAFT) polymerization. pH-switch and single emulsionsolvent evaporation post-polymerization processing methods are used to prepare benzaldehyde-functionalized PEGylated $\mathrm{pH}$-responsive nanoparticles with diameters of 180230nm. After nanoparticle formation, the benzaldehyde groups on the surface are shown to react with an Alexa Fluor 488 hydroxylamine dye through oxime bond formation, illustrating the potential for these particles to be surface-functionalized with biologically important molecules, such as fluorescent dyes for tracking their intracellular fate or antibodies for
\end{abstract}


targeted therapy. Encapsulation of Nile Red and rhodamine 6G dyes is performed during the post-polymerization processing step for nanoparticle formation. Nanoparticles with a fluorescent cargo were shown to be successfully internalized in both A2780 ovarian cancer and A549 lung epithelial human cells in vitro, further illustrating the potential for these formulations to be used as triggered release therapeutic drug delivery vehicles.

Keywords: Nanoparticles; pH-responsive; RAFT; conjugation; benzaldehyde; block copolymer

\section{Introduction}

The discovery of living radical polymerization techniques, such as reversible addition-fragmentation chain transfer (RAFT) polymerization [1-3], has allowed chemists to prepare well-defined polymers with low polydispersity. Intricate polymer structures, such as amphiphilic block copolymers, can be prepared easily as a consequence of the 'living' nature of these RAFT polymerizations [4]. Amphiphilic diblock copolymers can spontaneously self-assemble [5-8] to an array of different morphologies in aqueous solution, including spherical micelles, cylindrical micelles (worms), vesicles (polymersomes) and other intermediate structures, such as lamellae and jellyfish. Of these, micelles and vesicles are the most commonly reported in the literature for encapsulation of small molecules within their structures.

The amphiphilic diblock copolymer nanostructure morphology is dependent on three factors [9]; the Flory-Huggins interaction parameter, which defines the degree of incompatibility between the two blocks, the relative volume fraction of the hydrophilic and hydrophobic blocks, and the total degree of polymerization of the block copolymer. 
As such, increasing the length of the hydrophobic block while keeping the hydrophilic block length constant, is one method of controlling the type of nanostructure formed in solution [10].

PEG-based polymers are commonly used in preparing polymer nanoparticles for biomedical applications. This is due to the highly hydrophilic nature of PEG-based polymers and their ability to endow the polymer nanoparticles with 'stealth' properties that reduce clearance by the reticuloendothelial system [11], resulting in longer blood circulation times for encapsulated therapeutics.

Functionalization of amphiphilic block copolymers [12] with reactive groups is essential for chemically attaching biologically important molecules such as drugs [13], dyes [14-16], proteins [17-19], antibodies [20] and metals [21,22] on their nanostructures. This opens up a diverse range of applications for amphiphilic block copolymer nanoparticles that otherwise would be inaccessible, including biosensing [15,17,23], cell targeting for drug delivery [20,24], and medical imaging [21].

The benzaldehyde functional group is one that has been recently explored for functionalization of PEG-based block polymers [20,25,26]. Wooley et al reported poly(ethylene oxide)- $b$-poly(4-vinyl benzaldehyde) amphiphilic diblock polymer vesicles bearing benzaldehyde groups in their vesicular walls that were used to bind a fluorescein dye using reductive amination chemistry [26]. The same researchers showed that the nanoparticle stability was improved by cross-linking the benzaldehydefunctionalized nanoparticles using the same chemistry. Mao et al. used benzaldehydefunctionalized poly(2-(diisopropylamino)ethyl methacrylate)- $b$-p(oligo(ethylene glycol) methacrylate-st-para-formyl phenyl methacrylate) [PDPA- $b$-P(OEGMA-stpFPMA)] block copolymer micelles to attach the hydrophobic anti-cancer drug doxorubicin to the micelle surface [25]. 
In this study, we report the synthesis of a series of benzaldehyde containing $\mathrm{pH}$ responsive P(OEGMA-st-pFPMA)- $b$-PDPA block copolymers by RAFT polymerization in biologically compatible solvents. The benzaldehyde group, in the form of FPMA monomer, is incorporated in the hydrophilic (POEGMA) block of these block copolymers upon polymerization. These block copolymers were investigated for their ability to form polymeric nanoparticles by two different methodologies; selfassembly by pH-switch [27] and single emulsion-solvent evaporation [28-30]. The hydrophilic P(OEGMA-st-pFPMA) block endows the resulting nanoparticles with a reactive benzaldehyde group that protrudes from the hydrophilic nanoparticle surface. As shown in our previous work [20], this allows subsequent attachment of a biologically important molecule, such as an antibody, on the nanoparticle surface. This can be achieved, for example, through oxime bond formation between the benzaldehyde group on the nanoparticle surface and an aminooxy group of the molecule [20,31]. The PDPA hydrophobic (at neutral $\mathrm{pH}$ ) block, with a $\mathrm{p} K_{\mathrm{a}}$ value of $\sim 6.4$ [32], can provide to the polymer nanoparticles a $\mathrm{pH}$-responsive triggered release mechanism for encapsulated therapeutics at low $\mathrm{pH}$ values. This is the case since at $\mathrm{pH}$ values lower than 6.4 , the PDPA block is protonated, and therefore becomes hydrophilic, leading to the collapse of the nanoparticle structure.

\section{Experimental section}

\subsection{Materials}

All reagents were used as received unless otherwise stated. 4-Cyano-4 (phenylcarbonothioylthio)pentanoic acid (CADB, >97\%), 4,4'-azobis(4-cyanovaleric acid) (ACVA, $\geq 98 \%$ ), dichloromethane (99\%), ethanol (pure, anhydrous, $\geq 99.5 \%$ ), methanol (99.7\%), dimethyl sulfoxide (DMSO, $\geq 99.5 \%)$, chloroform- $d$ ( $\mathrm{CDCl}_{3}$, 
99.5\%), deuterium oxide $\left(\mathrm{D}_{2} \mathrm{O}, \geq 99.9 \%{ }^{2} \mathrm{H}\right.$ content), deuterium chloride (DCl, $35 \%$ w/w in $\mathrm{D}_{2} \mathrm{O}, \quad \geq 99.0 \% \quad{ }^{2} \mathrm{H} \quad$ content), hydrochloric acid $(\mathrm{HCl}$, analytical grade), poly(vinylalcohol) (PVA, average molecular weight of $13000-23000 \mathrm{~g} \mathrm{~mol}^{-1}, 98 \%$ hydrolyzed), tetrahydrofuran (THF, HPLC grade, $\geq 99.9 \%)$, triethylamine $(\geq 99 \%)$, butylated hydroxytoluene (BHT, >99\%), Nile Red (technical grade), paraphenylenediamine $(p-\mathrm{PDA}, \geq 99 \%)$ and rhodamine $6 \mathrm{G}(\sim 95 \%)$ were purchased from Sigma-Aldrich (UK). Sodium hydroxide $(\mathrm{NaOH},>98 \%)$ and deuterated methanol (methanol- $d_{4}$, MeOD, 99.8\%) were obtained from VWR International. Methacryloyl chloride $(\geq 97 \%)$ was purchased from Fluka Chemicals. Phosphate buffer saline (PBS) tablets were purchased from GIBCO - ThermoFisher Scientific (UK). Alexa Fluor ${ }^{\mathrm{TM}}$ 488 hydroxylamine dye was obtained from Invitrogen ${ }^{\mathrm{TM}}$ - ThermoFisher Scientific (UK). DPA $(\geq 97 \%)$ was purchased from Scientific Polymer Products Inc. (USA). OEGMA (MPEG 350) was kindly donated by GEO Specialty Chemicals (UK). Spectra/Por ${ }^{\circledR} 6$ dialysis tubing with molecular weight cut-off (MWCO) of 1000 Da was purchased from Spectrum Labs (USA). Both DPA and OEGMA monomers were passed through a basic alumina column before use to remove any radical inhibitors. The pFPMA monomer was prepared in-house, according to the synthetic procedure by Garcia- Acosta et al. [33].

\subsection{Synthesis of benzaldehyde-functionalized P(OEGMA-st-pFPMA) macro-chain} transfer agent (macro-CTA)

Typically, synthesis of a $\mathrm{P}\left(\mathrm{OEGMA}_{23}-\mathrm{st}\right.$-pFPMA $\left.\mathrm{p}_{1}\right)$ macro-CTA was performed at a molar ratio $[\mathrm{CADB}]:[\mathrm{OEGMA}]:[\mathrm{pFPMA}]:[\mathrm{ACVA}]$ of $1: 25: 1: 0.25$ and a $50 \% \mathrm{w} / \mathrm{w}$ solids content. The reaction was carried out as follows. CADB (137 mg, $0.50 \mathrm{mmol}$ ), OEGMA (5.63 mg, $12.50 \mathrm{mmol}$ ), and pFPMA (95 mg, $0.50 \mathrm{mmol}$ ) were added to a 25 $\mathrm{mL}$ round bottom flask. Subsequently, ethanol $(7.46 \mathrm{~mL})$ was added to the flask, which 
was then equipped with a rubber septum and a magnetic stirrer bar. The resulting solution was purged with nitrogen gas for $20 \mathrm{~min}$. ACVA $(35.04 \mathrm{mg}, 0.125 \mathrm{mmol})$ was then added to the flask. The solution was purged again with nitrogen gas for $10 \mathrm{~min}$ before the flask was immersed in an oil bath at $78{ }^{\circ} \mathrm{C}$. The reaction proceeded for $4 \mathrm{~h}$ and was quenched by cooling at room temperature and exposing the contents of the flask to air. The crude product was dialyzed against methanol (MWCO 1000, 7-8 times, 12 h) and the resulting solution was dried under vacuum. The pure macro-CTA was obtained as a pink/red viscous liquid. In total, four macro-CTAs were prepared. Each of the macro-CTAs were characterized by ${ }^{1} \mathrm{H} \mathrm{NMR}\left(\mathrm{CDCl}_{3}\right)$, giving monomer percentage conversions from $87.2 \%$ to $92.0 \%$, and size exclusion chromatography (SEC) in THF, giving number-average molecular weight $\left(M_{n}\right)$ values ranging from 9600 to $10400 \mathrm{~g}$ mol$^{-1}$ and dispersity $(Ð)$ values of $1.12-1.14$.

2.3. Synthesis of the $p H$-responsive benzaldehyde-functionalized amphiphilic P(OEGMAst-pFPMA)-b-PDPA block copolymer

The protocol followed for the synthesis of $\mathrm{P}\left(\mathrm{OEGMA}_{23}-s t-\mathrm{pFPMA}_{1}\right)-b-\mathrm{PDPA}_{\mathrm{x}}$ block copolymers (where $\mathrm{x}=151,167,186,197$ or 235 ) at $50 \% \mathrm{w} / \mathrm{w}$ solids content was as follows. In a typical reaction to prepare $\mathrm{P}\left(\mathrm{OEGMA}_{23}-s t-\mathrm{pFPMA}_{1}\right)-b-\mathrm{PDPA}_{151}$ amphiphilic block copolymer, the $\mathrm{P}\left(\mathrm{OEGMA}_{23}-s t\right.$-pFPMA 1$)$ macro-CTA $(0.50 \mathrm{~g}, 0.05$ mmol) and DPA monomer $(1.7 \mathrm{~mL}, 1.77 \mathrm{~g}, 8.32 \mathrm{mmol})$ were added in a $25 \mathrm{~mL}$ round bottom flask, equipped with a magnetic stirrer bar and rubber septum. Ethanol (11.55 $\mathrm{mL}$ ) was then added and the mixture was degassed with nitrogen gas for $20 \mathrm{~min}$. Then, ACVA (4.27 mg, $0.02 \mathrm{mmol})$ was added to give a final molar ratio [macroCTA]:[DPA]:[ACVA] of 1:180:0.33. The mixture in the flask was bubbled with nitrogen gas for a further $20 \mathrm{~min}$. The flask was then immersed in an oil bath preset at $78{ }^{\circ} \mathrm{C}$. The reaction was left stirring for $26 \mathrm{~h}$ and was quenched by cooling the solution 
to room temperature followed by exposure to air. The final polymerization reaction product was characterized by ${ }^{1} \mathrm{H}$ NMR spectroscopy $\left(\mathrm{CDCl}_{3} / \mathrm{MeOD}=3: 1 \mathrm{v} / \mathrm{v}\right)$, giving a DPA monomer conversion of $84.0 \%$. The purified final block copolymer was obtained after dialyzing the crude reaction mixture against methanol (MWCO 1,000; 7-8 times, $24 \mathrm{~h}$ ) and removal of methanol under reduced pressure. The purified polymers were characterized by ${ }^{1} \mathrm{H} \mathrm{NMR}\left(\mathrm{CDCl}_{3} / \mathrm{MeOD}=3: 1 \mathrm{v} / \mathrm{v}\right)$ and $\mathrm{SEC}(\mathrm{THF})$. The same process was followed for the synthesis of all amphiphilic block copolymers. DPA monomer conversions of $75.8 \%-84.0 \%$ were obtained by ${ }^{1} \mathrm{H} \mathrm{NMR}\left(\mathrm{CDCl}_{3} / \mathrm{MeOD}=3: 1 \mathrm{v} / \mathrm{v}\right)$ for the amphiphilic block copolymers at the end of the polymerization reaction. The purified polymers appeared to have $M_{\mathrm{n}}$ values of $30,000-37,400 \mathrm{~g} \mathrm{~mol}^{-1}$ and $Ð$ values of 1.40 1.51 by SEC (THF).

\subsection{Polymer characterization}

All proton nuclear magnetic resonance $\left({ }^{1} \mathrm{H}\right.$ NMR) spectra were recorded using a 400 $\mathrm{MHz}$ Bruker Avance spectrometer.

SEC data were obtained using an Agilent 1260 Infinity GPC system. The instrument setup was comprised of a guard column and two Agilent PL gel $5 \mu \mathrm{m}$ MIXED-C columns connected in series operating at $25{ }^{\circ} \mathrm{C}$, and a refractive index detector maintained at $30{ }^{0} \mathrm{C}$, allowing for the determination of the molecular weight distributions (MWDs) of the amphiphilic block copolymers and their copolymer precursors. The eluent used was tetrahydrofuran (THF) containing $2.0 \% \mathrm{v} / \mathrm{v}$ triethylamine and $0.05 \% \mathrm{w} / \mathrm{v}$ BHT inhibitor at a flow rate of $1.0 \mathrm{~mL} \mathrm{~min}{ }^{-1}$. The flow rate marker used was DMSO. A series of ten near-monodisperse poly(methyl methacrylate) standards from Agilent, with molecular weights (MWs) of 1,010, 1,950, $6,850,13,900,31,110,68,750,137,800,320,000,569,000$ and $1,048,000 \mathrm{~g} \mathrm{~mol}^{-1}$ were 
used to calibrate the RI detector. Cirrus ${ }^{\mathrm{TM}}$ software from Agilent was used for the analysis of the SEC chromatograms.

\subsection{Polymeric nanoparticle formation and dye encapsulation by $\mathrm{pH}$-switch}

A pH-switch method was used to facilitate nanoparticle formation [27]. $10 \mathrm{~mL}$ of chloroform were added to a glass vial containing $22 \mathrm{mg}$ of benzaldehyde functionalized $\mathrm{P}\left(\mathrm{OEGMA}_{\mathrm{x}}\right.$-st-pFPMA 1$)-b$-PDPAy amphiphilic block copolymer and a magnetic stirrer bar. The mixture was left to stir until the polymer was dissolved in the organic solvent and the resulting solution $\left(2.2 \mathrm{mg} \mathrm{mL} \mathrm{mL}^{-1}\right.$ ) was placed in a desiccator under vacuum overnight. After chloroform removal, a thin polymer film was obtained at the bottom of the glass vial. $10 \mathrm{~mL}$ of $0.1 \mathrm{M}$ PBS buffer ( $\mathrm{pH} 7.4$ ) and 3 drops of $2 \mathrm{M} \mathrm{HCl}$ solution were added to the glass vial to dissolve the polymer film. The solution was left under stirring until the polymer was completely dissolved and a transparent solution was obtained ( $\mathrm{pH}$ value in the range of 1.5 to 2.0$)$. Subsequently, the solution $\mathrm{pH}$ value was increased to 7.4 by slow dropwise addition of $1.0 \mathrm{M} \mathrm{NaOH}$, with intermittent sonication (Elmasonic S 30), to give a cloudy (non-transparent) suspension, indicating formation of self-assembled nanoparticles. Further sonication for 10 min was then used to break down any precipitates formed during the $\mathrm{pH}$-switch process, before determination of the nanoparticle morphology.

For encapsulation of Nile Red by $\mathrm{pH}$-switch, $20 \mu \mathrm{L}$ of a $0.25 \mathrm{mg} \mathrm{mL}^{-1}$ solution of Nile Red in chloroform was added to $10 \mathrm{~mL}$ of chloroform before solvent removal as detailed previously. The same procedure described above was then followed for the preparation of self-assembled Nile Red nanoparticles $\left(2.2 \mathrm{mg} \mathrm{mL}^{-1}\right)$ using the $\mathrm{P}\left(\mathrm{OEGMA}_{22}-s t\right.$-pFPMA 1 )- $b$-PDPA 197 block copolymer. 
The final suspension was then diluted to $1 \mathrm{mg} \mathrm{mL}^{-1}$ and the nanoformulation was subjected to three centrifugal wash steps performed in PBS buffer (20 min, 20,000 g, 4 $\left.{ }^{\mathrm{o}} \mathrm{C}\right)$ to remove any free dye.

In order to ensure sterility, all glassware, stirrer bars and aqueous solutions were autoclaved before use. Additionally, all $\mathrm{pH}$-switch formulated nanoparticles were produced inside a class II laminar flow hood.

2.6. Polymeric nanoparticle formation and dye encapsulation by single emulsion-solvent evaporation

Nanoparticles were prepared using a single emulsion-solvent evaporation approach.[20,28-30] $1 \mathrm{~mL}$ of dichloromethane was used to dissolve $20 \mathrm{mg}$ of benzaldehyde functionalized P(OEGMA-st-pFPMA)- $b$-PDPA amphiphilic block copolymer. The resulting polymer solution (organic phase) was subsequently added dropwise to a $7 \mathrm{~mL}$ aqueous solution of $2.5 \% \mathrm{w} / \mathrm{v}$ polyvinyl alcohol (PVA) in PBS buffer ( $\mathrm{pH}$ 7.4). In order to initiate emulsion formation, the solution was pulse sonic ated on ice for $90 \mathrm{sec}$ using a Model 120 Sonic Dismembrator (Fisher Scientific). The emulsion formed post-sonication was then stirred overnight to enable evaporation of the dichloromethane. Following solvent evaporation, nanoparticles were washed via $3 \times 20$ min sequential centrifugation wash steps performed at 20,000 $\mathrm{g}$ in $0.1 \mathrm{M}$ PBS buffer. The final nanoparticle pellet was resuspended in PBS buffer as required.

To produce fluorescently labeled nanoparticles, 0.2\% (w/v) rhodamine 6G (in 100 $\mu \mathrm{L}$ DCM) was added into the organic phase (final concentration $0.02 \% \mathrm{w} / \mathrm{v}$ ).

To ensure sterility, glassware, stirrer bars and aqueous solutions were autoclaved before use and all single emulsion solvent evaporation formulated nanoparticles were produced inside a class II laminar flow hood. 


\subsection{Polymeric nanoparticle size determination}

Dynamic light scattering (DLS) was used to assess the hydrodynamic diameter and polydispersity index (PDI) of the nanoparticles. The intensity-average sphere equivalent diameter of the amphiphilic block copolymer nanoparticles was determined using a Malvern Zetasizer Nano Series ZS instrument. This was operating at $25{ }^{\circ} \mathrm{C}$ with a 633 $\mathrm{nm}$ (red) laser diode and a detection angle of $173^{\circ}$ (back scattering). Analytical readings were carried out, in triplicate, with nanoparticles resuspended at $1 \mathrm{mg} \mathrm{mL}^{-1}$ in PBS buffer and the collected data averaged.

For scanning electron microscopy (SEM) imaging of samples prepared by single emulsion-solvent evaporation method, nanoparticles were suspended in water at $5 \mathrm{mg}$ $\mathrm{mL}^{-1}$. 5 drops of the nanoparticle solution were added to double-sided copper tape, fixed to an aluminium stub. The samples were allowed to dry overnight. Nanoparticles were then sputter coated with gold and imaged using an FEI Quanta 250 FEG - Environmental Scanning Electron Microscope (E-SEM).

Transmission electron microscopy (TEM) imaging of the nanoparticle morphologies prepared by the pH-switch method was performed using a JEOL 1200 EXII instrument equipped with a numerical camera and operating at $120 \mathrm{kV}$. For TEM sample preparation, $5.0 \mu \mathrm{L}$ of a dilute amphiphilic block copolymer nanoparticle solution $(0.2$ $\mathrm{mg} \mathrm{mL}^{-1}$ ) were placed onto a carbon-coated copper grid and stained using a $99.98 \%$ aqueous ammonium molybdate solution. The samples were then dried under ambient conditions.

\subsection{Assessment of pH dependent nanoparticle collapse}

P(OEGMA-st-pFPMA)- $b$-PDPA amphiphilic block copolymer nanoparticles were suspended in buffer solutions at neutral (7.4) and acidic (4.0) pH. Following 
resuspension, nanoparticles were assessed in terms of their physical characteristics via DLS (as detailed previously). Nanoparticle suspensions were also assessed visually.

\subsection{Cell line viability}

HCT116 cells were acquired from the American Type Culture Collection (ATCC) and cultured in high glucose DMEM supplemented with 10\% FCS. Cell viability was assessed via methylthiazolyldiphenyltetrazolium bromide (MTT) assay. HCT116 cells were seeded in 96-well plates at 2500 cells/well and allowed to adhere. Cells were subsequently treated with P(OEGMA-st-pFPMA)- $b$-PDPA amphiphilic block copolymer nanoparticles and incubated at $37{ }^{\circ} \mathrm{C}$ for $48 \mathrm{~h}$. Following the completion of the treatment period, MTT reagent $\left(0.5 \mathrm{mg} \mathrm{mL}^{-1}\right)$ was added to each well and left for 2 $\mathrm{h}$ to permit formazan crystals formation. The media was subsequently removed and DMSO was added. Absorbance was measured at $570 \mathrm{~nm}$ and cell viability of P(OEGMA-st-pFPMA)- $b$-PDPA amphiphilic block copolymer treated cells was expressed relative to that of control cells.

\subsection{Attachment of fluorescent dye on the nanoparticle surface}

In order to assess the ability of the reactive benzaldehyde group of the pFPMA monomer unit in the amphiphilic block copolymer structure to conjugate moieties to the exterior of the prepared nanoparticles, Alexa Fluor ${ }^{\mathrm{TM}} 488$ hydroxylamine dye was used as a model compound. The dye was attached to P(OEGMA $22-s t-$ pFPMA $\left._{1}\right)-b-$ PDPA $_{186}$ nanoparticles via the formation of stable oxime bonds. For the conjugation reaction, $1 \%$ $\mathrm{w} / \mathrm{w}$ or $3 \% \mathrm{w} / \mathrm{w}$ Alexa Fluor ${ }^{\mathrm{TM}} 488$ hydroxylamine and 1\% w/w $p$-PDA catalyst were added to a $1 \mathrm{mg} \mathrm{mL}^{-1} \mathrm{P}(\mathrm{OEGMA-st-pFPMA})$ - $b$-PDPA nanoparticle solution in PBS buffer. The resulting mixture was moderately stirred for $36 \mathrm{~h}$. The catalyst and unbound dye were removed from the conjugated nanoparticles by sequential centrifugation wash steps $(3 \times 20 \mathrm{~min})$ at $20000 \mathrm{~g}$ in $0.1 \mathrm{M}$ PBS buffer. For examining the dye attachment, 
the nanoparticles were dissolved at a concentration of $1 \mathrm{mg} \mathrm{mL}^{-1}$ in acetonitrile/DMSO (1:1) and the fluorescence of the sample was assessed (ex $488 / \mathrm{em} 518 \mathrm{~nm}$ ). The SEC (THF) chromatograms of the conjugated polymer samples are shown in Fig. S6 together with the respective non-conjugated sample. The conjugated samples appeared to have $M_{\mathrm{n}}$ and $Ð$ values by SEC of $36,100 \mathrm{~g} \mathrm{~mol}^{-1}$ and 1.32 for the $1 \% \mathrm{w} / \mathrm{w}$ dye concentration used in the reaction, and 44,300 $\mathrm{g} \mathrm{mol}^{-1}$ and 1.34 for the $3 \% \mathrm{w} / \mathrm{w}$ dye concentration.

\subsection{In vitro nanoparticle uptake}

A549 and A2780 cells were seeded at 40,000 per well on an eight-well glass culture slide (BD Falcon) and allowed to adhere overnight. In order to assess nanoparticle uptake, cells were treated with rhodamine $6 \mathrm{G}$ loaded nanoparticles $\left(500 \mu \mathrm{g} \mathrm{mL} \mathrm{mL}^{-1}\right.$ ) produced via the single emulsion-solvent evaporation methodology. Cells were incubated at $37{ }^{\circ} \mathrm{C}$ for $2 \mathrm{~h}$. On completion of the treatment period, cells were washed with PBS (3x) and fixed with $4 \%$ w/v paraformaldehyde in PBS for 20 min. Following further washes in PBS $(3 \mathrm{x})$, cells were permeabilized with $0.5 \% \mathrm{v} / \mathrm{v}$ Triton $\mathrm{X}-100$ in PBS for $5 \mathrm{~min}$. Cells were then washed with PBS (3x) and coverslips were added postapplication of Vectashield antifade mounting medium with DAPI (Vector Laboratories). Images were obtained using a Leica SP8 confocal microscope running with Leica LAS $\mathrm{X}$ software (Leica, UK) and operating with a HCX PL APO 1.4-0.6NA 63x oil immersion objective zoomed 1-4x with a 1024 x 1024 frame and $400 \mathrm{~Hz}$ scan speed.

\section{Results and discussion}

In order to investigate the change in benzaldehyde-functionalized polymer nanoparticle morphology with increasing the hydrophobic in neutral $\mathrm{pH}$ PDPA block length, a series of P(OEGMA-st-pFPMA)- $b$-PDPA amphiphilic block copolymers with different degrees of polymerization (DPs) of the DPA block were prepared. Mao et al. 
previously reported the formation of $\mathrm{pH}$-responsive micelles by self-assembly of P(OEGMA-st-pFPMA)- $b$-PDPA amphiphilic block copolymers prepared by RAFT polymerization [25]. The polymers were prepared by chain extension of a PDPA macroCTA with a mixture of OEGMA and pFPMA in 1,4-dioxane. However, in a recent study by Prat et al., it was reported that 1,4-dioxane is a 'hazardous' solvent, and should be avoided where possible [34]. Since the same authors reported also that alcohols, such as ethanol, were ranked as 'recommended' solvents, this was the solvent of choice for the polymerization reactions in this work. Therefore, in order to prepare benzaldehydefunctionalized amphiphilic block copolymers using a more biologically acceptable method, the syntheses of both the P(OEGMA-st-pFPMA) macro-CTAs and their corresponding P(OEGMA-st-pFPMA)-b-PDPA amphiphilic block copolymers were performed in ethanol (Scheme 1). The presence of PEG (in the OEGMA monomer units) can shield the polymers from protein opsonization and can increase their circulation half-life [35,36]. The benzaldehyde group of the pFPMA monomer can react with aminooxy-functionalized molecules to give oxime-bound conjugates [31]. The PDPA block ( $\left.K_{\mathrm{a}} \sim 6.4\right)$ [27,32,37] becomes hydrophilic (protonated) at low $\mathrm{pH}$, causing collapse of the nanoparticles that can potentially release any encapsulated molecules in the nanoparticle structure as endosomal $\mathrm{pH}$ drops following endocytosis. After synthesizing the amphiphilic block copolymers, two different methodologies were utilized for nanoparticle preparation and dye encapsulation: pH-switch [27] and single emulsion-solvent evaporation [28-30]. The nanoparticle collapse in acidic conditions, toxicity and attachment of dye on the nanoparticle surface were evaluated. 

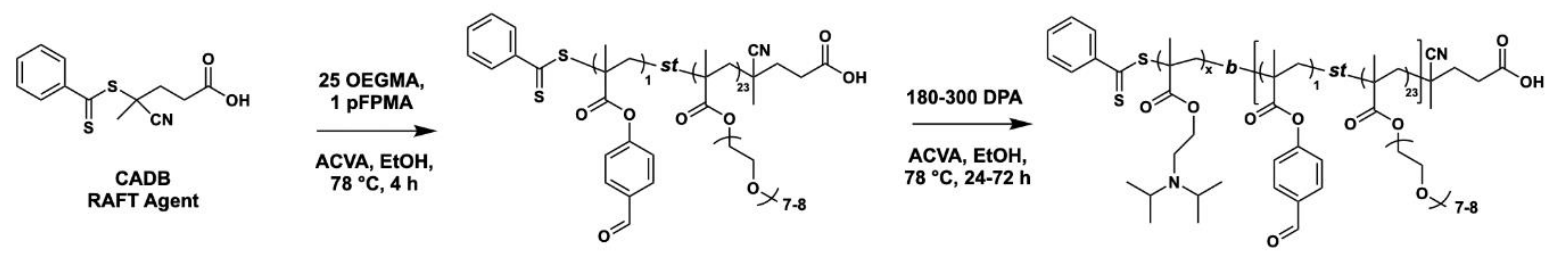

Scheme 1. Synthesis of P(OEGMA-st-pFPMA) macro-CTA by RAFT solution polymerization of OEGMA/pFPMA mixture and its subsequent chain extension with DPA monomer to produce benzaldehyde-functionalized P(OEGMA-st-pFPMA)- $b$ PDPA amphiphilic block copolymers.

\subsection{Preparation of benzaldehyde-functionalized P(OEGMA-st-pFPMA) macro-CTAs}

A series of (POEGMA-st-pFPMA) macro-CTAs were prepared that were then chain-extended with DPA monomer to give the (POEGMA-st-pFPMA)- $b$-PDPA amphiphilic block copolymers. The reaction products of the syntheses of the macroCTAs were characterized by ${ }^{1} \mathrm{H}$ NMR spectroscopy $\left(\mathrm{CDCl}_{3}\right)$. As shown in Table $1,{ }^{1} \mathrm{H}$ NMR percentage monomer conversions were typically higher than $87 \%$ at a reaction time of $4 \mathrm{~h}$. These were obtained by comparing the area under the characteristic monomer methacrylic peaks at 5.58 and $6.14 \mathrm{ppm}$ to the area of the combined broad polymer/monomer signals of $-\mathrm{COCH}_{2}$ at $4.09 \mathrm{ppm}$.

\section{Table 1}

Polymerization reaction times, ${ }^{1} \mathrm{H}$ NMR monomer conversions and molecular weights, SEC number-average molecular weight $\left(M_{\mathrm{n}}\right)$ and dispersity $(\nexists)$ for the synthesized (POEGMA $-s t$ $\left.\mathrm{pFPMA}_{1}\right)$ RAFT macro-CTAs $(\mathrm{x}=22$ and 23) and their corresponding (POEGMA $\mathrm{x}-$ stpFPMA $\left._{1}\right)-b$-PDPAy amphiphilic block copolymers $(\mathrm{y}=151,167,186,197$ and 235) prepared via RAFT solution polymerization in ethanol at $78{ }^{\circ} \mathrm{C}$, and DLS hydrodynamic diameter $\left(D_{\mathrm{h}}\right)$ and polydispersity index (PDI) values of nanoparticle morphologies in PBS buffer prepared by $\mathrm{pH}$-switch and single emulsion-evaporation methods. 


\begin{tabular}{|c|c|c|c|c|c|c|c|c|c|c|}
\hline \multirow[t]{3}{*}{ entry } & \multirow[t]{3}{*}{ polymer structure } & \multirow{3}{*}{$\begin{array}{l}\text { reaction } \\
\text { time }(h)\end{array}$} & \multicolumn{2}{|c|}{${ }^{1} \mathrm{H}$ NMR } & \multicolumn{2}{|c|}{ SEC } & \multicolumn{4}{|c|}{ DLS $^{\mathrm{d})}$} \\
\hline & & & \multirow[t]{2}{*}{$\begin{array}{l}\% \text { monomer } \\
\text { conversion }^{\text {a) }}\end{array}$} & \multirow[t]{2}{*}{$\begin{array}{c}\mathrm{MW}^{\mathrm{b})} \\
\left(\mathrm{g} \mathrm{mol}^{-1}\right)\end{array}$} & \multirow[t]{2}{*}{$\begin{array}{c}M_{\mathrm{n}}^{\mathrm{c})} \\
\left(\mathrm{g} \mathrm{mol}^{-1}\right)\end{array}$} & \multirow[t]{2}{*}{$\bigoplus^{\mathrm{c})}$} & \multicolumn{2}{|c|}{ pH-switch method } & \multicolumn{2}{|c|}{$\begin{array}{c}\text { single emulsion- } \\
\text { evaporation } \\
\text { method }\end{array}$} \\
\hline & & & & & & & $D_{\mathrm{h}}$ & PDI & $D_{\mathrm{h}}$ & PDI \\
\hline 1 & POEGMA $_{23}-s t$-pFPMA 1 & 4 & 90.6 & 10,800 & 10,400 & 1.13 & $\begin{array}{ll}--- \\
\end{array}$ & $\begin{array}{ll}-- \\
--\end{array}$ & $\begin{array}{ll}-- \\
--\end{array}$ & $\begin{array}{ll}-- \\
--\end{array}$ \\
\hline 2 & $\mathrm{POEGMA}_{22}-s t$-pFPMA 1 & 4 & 87.2 & 10,400 & 9,900 & 1.14 & --- & --- & --- & --- \\
\hline 3 & POEGMA $_{23}-s t$-pFPMA 1 & 4 & 92.0 & 10,800 & 9,600 & 1.12 & --- & --- & --- & --- \\
\hline 4 & POEGMA $_{22}-s t-$ pFPMA $_{1}$ & 4 & 89.9 & 10,400 & 9,600 & 1.12 & --- & --- & --- & --- \\
\hline 5 & $\begin{array}{c}\mathrm{P}\left(\mathrm{OEGMA}_{23}-s t-\right. \\
\left.\mathrm{pFPMA}_{1}\right)-b-\mathrm{PDPA}_{151}\end{array}$ & 26 & 84.0 & 41,100 & 30,000 & 1.47 & 182.2 & 0.231 & 237.8 & 0.093 \\
\hline 6 & $\begin{array}{c}\mathrm{P}\left(\mathrm{OEGMA}_{23}-s t-\right. \\
\left.\mathrm{pFPMA}_{1}\right)-b-\mathrm{PDPA}_{167}\end{array}$ & 24 & 79.6 & 45,300 & 33,500 & 1.40 & 199.2 & 0.397 & 255.0 & 0.134 \\
\hline 7 & $\begin{array}{c}\mathrm{P}\left(\mathrm{OEGMA}_{22}-s t-\right. \\
\left.\mathrm{pFPMA}_{1}\right)-b-\mathrm{PDPA}_{186}\end{array}$ & 24 & 80.9 & 50,100 & 34,300 & 1.47 & 228.7 & 0.336 & 231.5 & 0.070 \\
\hline 8 & $\begin{array}{c}\mathrm{P}\left(\mathrm{OEGMA}_{22}-s t-\right. \\
\left.\mathrm{pFPMA}_{1}\right)-b-\mathrm{PDPA}_{197}\end{array}$ & 26 & 78.6 & 52,400 & 34,500 & 1.51 & 263.9 & 0.308 & 230.4 & 0.119 \\
\hline 9 & $\begin{array}{c}\mathrm{P}\left(\mathrm{OEGMA}_{23}-s t-\right. \\
\left.\mathrm{pFPMA}_{1}\right)-b-\mathrm{PDPA}_{235}\end{array}$ & 48 & 75.8 & 60,900 & 37,400 & 1.46 & 226.5 & 0.251 & 230.2 & 0.047 \\
\hline
\end{tabular}

Therefore, based on the ${ }^{1} \mathrm{H}$ NMR monomer conversions, $\mathrm{P}\left(\mathrm{OEGMA}_{23}-\right.$ st-pFPMA 1$)$ copolymer macro-CTAs with a mean DP of OEGMA of 22-23 and MWs in the range of 10,400 to $10,800 \mathrm{~g} \mathrm{~mol}^{-1}$ were synthesized. The purified (by dialysis in methanol) macro-CTAs were characterized by ${ }^{1} \mathrm{H}$ NMR (Fig. S1A, Fig. S2 and Table 1) and SEC (Fig. 1 and Table 1). After purification, the presence of the benzaldehyde proton at 10.0 ppm in the ${ }^{1} \mathrm{H}$ NMR spectra combined with the absence of any methacrylic monomer protons (Fig. S1A and Fig. S2), confirmed that the benzaldehyde monomer had been successfully incorporated into the P(OEGMA-st-pFPMA) macro-CTA chain. A small impurity was present at $5.49 \mathrm{ppm}$ of the $\mathrm{P}\left(\mathrm{OEGMA}_{23}-s t\right.$-pFPMA $\left.\mathrm{A}_{1}\right)$ macro-CTA spectra in $\mathrm{CDCl}_{3} / \mathrm{MeOD}$ mixture $3 / 1 \mathrm{v} / \mathrm{v}$ (Fig. $\mathrm{S} 2 \mathrm{~A}$ ) and in $\mathrm{D}_{2} \mathrm{O}$ (Fig. S2B). This was attributed to acetal formation caused by the reaction of the benzaldehyde group with excess ethanol, which was used as a solvent during the polymerization and/or methanol solvent used during the purification of the macro-CTA by dialysis. As expected, addition of DCl in the (OEGMA $23-s t$-pFPMA $A_{1}$ ) macro-CTA ${ }^{1} \mathrm{H}$ NMR sample in $\mathrm{D}_{2} \mathrm{O}$ (Fig. S2B) to give 
a $2 \% \mathrm{w} / \mathrm{w} \mathrm{DCl}$ in $\mathrm{D}_{2} \mathrm{O}$ solution (acidic conditions) resulted in disappearance of the peak at $5.49 \mathrm{ppm}$ (Fig. S2C), since acetals are known to hydrolyze in the presence of an acid [38]. This can lead to formation of the initial aldehyde group. SEC (THF) analysis showed that the macro-CTAs were prepared with good control. More specifically, the SEC chromatograms (Fig. 1, samples 1-4) appeared to have narrow MWDs with low polydispersities $(\nexists \sim 1.1$, Table 1, entries 1-4). The small shoulder that was obtained in the macro-CTA SEC chromatograms (Fig. 1, samples 1-4) at higher MW (lower retention times) can be due to ethylene glycol dimethacrylate (EGDMA) cross-linker present in the OEGMA monomer as impurity from its manufacture. The traces of EGDMA in the monomer can result in chain-chain coupling reactions between macroCTA chains. However, these coupling reactions did not seem to affect significantly the formation of the block copolymer in the subsequent polymerization step. As shown in Table 1 (entries 1-4), the $M_{\mathrm{n}}$ values obtained by SEC analysis for the macro-CTAs were found to be in good agreement with the MWs calculated from ${ }^{1} \mathrm{H}$ NMR analysis.

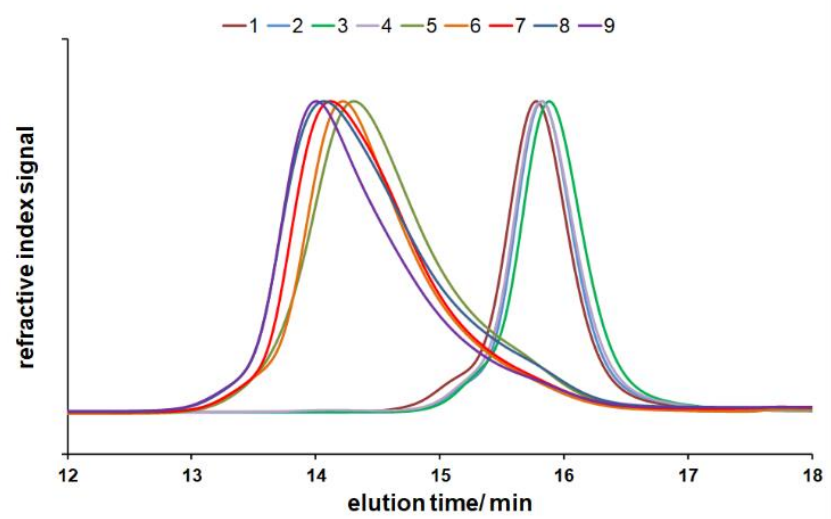

Fig. 1. SEC (THF) data for $\mathrm{P}\left(\mathrm{OEGMA}_{\mathrm{x}}-\right.$ st-pFPMA 1 ) macro-CTAs (samples $1-4$, Table 1 entries 1-4) and $\mathrm{P}\left(\mathrm{OEGMA}_{\mathrm{x}}-\mathrm{st}\right.$-pFPMA 1$)-b$-PDPA $\mathrm{Am}_{\mathrm{y}}$ amphiphilic diblock copolymers (samples 5-9, Table 1 entries 5-9). 
The benzaldehyde functionalized $\mathrm{P}\left(\mathrm{OEGMA}_{\mathrm{x}}-\right.$ st-pFPMA $\left.\mathrm{AF}_{1}\right)$ macro-CTAs were each chain extended using different (180-300) molar equivalents of DPA monomer. For this, RAFT polymerization at $78{ }^{\circ} \mathrm{C}$ in ethanol at $20 \% \mathrm{w} / \mathrm{w}$ solids content for $24-48 \mathrm{~h}$ was used to successfully prepare the (POEGMAx $-s t-$ pFPMA $\left._{1}\right)-b-$ PDPA $_{y}$ amphiphilic block copolymers (Table 1, entries 5-9) by chain extension of the $\mathrm{P}\left(\mathrm{OEGMA}_{\mathrm{x}}-\right.$ st-pFPMA 1$)$ macro-CTAs (Table 1, entries 1-4). Under these polymerization conditions, relatively high DPA monomer conversions $(76 \%-84 \%)$ by ${ }^{1} \mathrm{H}$ NMR were achieved (Table 1, entries 5-9). The appearance of the characteristic isopropyl protons of the DPA at 1.04 and $2.67 \mathrm{ppm}$ in the ${ }^{1} \mathrm{H}$ NMR spectra of the purified after dialysis in methanol $\mathrm{P}\left(\mathrm{OEGMA}_{\mathrm{x}}-\right.$ st-pFPMA 1$)-b-\mathrm{PDPA}_{\mathrm{y}} \quad$ samples $\quad\left(\mathrm{Fig} . \quad \mathrm{S} 1 \mathrm{~B}-\mathrm{F}, \quad 3 / 1 \quad \mathrm{v} / \mathrm{v} \quad \mathrm{CDCl}_{3} / \mathrm{MeOD}\right)$, confirmed their successful synthesis. SEC (THF) also confirmed the preparation of block copolymers. The SEC chromatograms of the block copolymers (Fig. 1, samples 5-9) showed a clear shift to shorter elution time as the DP of the DPA monomer increased, indicating a shift to successfully larger polymer MWs. The block copolymer SEC data (Table 1, entries 5-9) showed that high block lengths could be achieved by RAFT polymerization in ethanol (up to $\mathrm{DP}_{\mathrm{DPA}}=235$ was obtained). The polymers appeared to have molecular weight distributions (MWDs) (Fig. 1, samples 5-9), with $Ð$ values of 1.40-1.51 (Table 1, entries 5-9). The observed differences between the MW by ${ }^{1} \mathrm{H}$ NMR spectroscopy and the $M_{n}$ values from SEC can be attributed to interactions between the DPA side chains and the SEC columns, resulting in the tailing effect obtained for the peaks in the SEC chromatograms (Fig.1, samples 5-9), giving broader MWDs [16,20].

\subsection{Assessment of nanoparticle morphology and dye encapsulation by $\mathrm{pH}$-switch method}

A pH-switch post-polymerization methodology [27] was used to prepare benzaldehydefunctionalized amphiphilic block copolymer self-assemblies in sterile conditions. Since 
the benzaldehyde groups are incorporated in the hydrophilic block of the block copolymer, the nanostructures prepared by this methodology are expected to have exposed benzaldehyde groups on their surfaces that could be used to bind biologically important molecules, such as drugs [25], fluorescent dyes [26] or antibodies [20]. Also, they are expected to have $\mathrm{pH}$-responsive PDPA cores that could release encapsulated payloads in response to $\mathrm{pH}$ change. In principle, by increasing the DP of the hydrophobic (in neutral pH) PDPA block, it is possible to control the amphiphilic block copolymer nanoparticle morphology that can be formed by $\mathrm{pH}$-switch. Short hydrophobic blocks are known to be able to form micelles [39], whilst larger structures, such as worm-like micelles [40,41] and polymer vesicles [42] can be obtained with longer hydrophobic blocks. DLS data (Fig. 2) of the various $\mathrm{P}\left(\mathrm{OEGMA}_{\mathrm{x}}-s t\right.$-pFPMA 1$)-$ $b$-PDPAy amphiphilic diblock copolymer solutions $(1 \mathrm{mg} \mathrm{mL}-1,0.1 \mathrm{M} \mathrm{PBS,} \mathrm{pH} \sim 7.4)$ prepared by $\mathrm{pH}$-switch, showed changes in the observed morphology with increasing MW of the PDPA block.

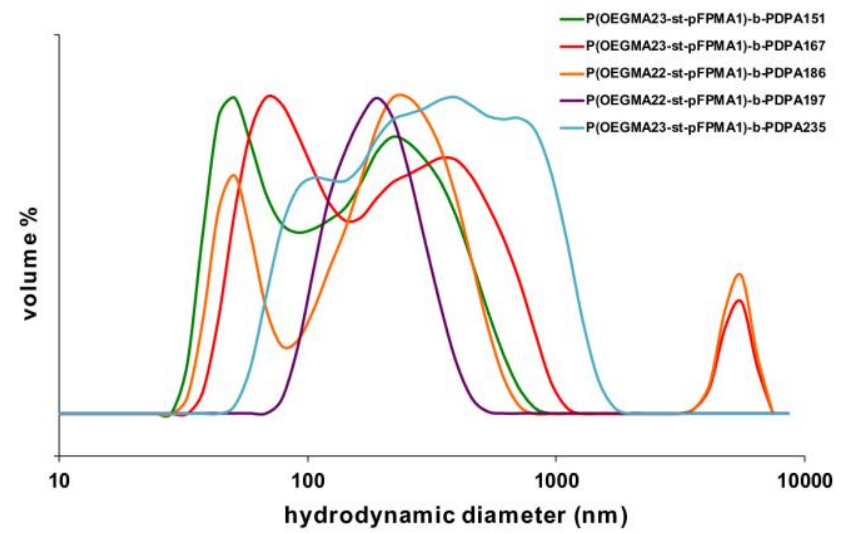

Fig. 1 DLS volume weighted diameter distribution of the $\mathrm{P}\left(\mathrm{OEGMA}_{\mathrm{x}}-s t-\mathrm{pFPMA}_{1}\right)-b-\mathrm{PDPA}_{\mathrm{y}}$ amphiphilic diblock copolymer morphologies $\left(1 \mathrm{mg} \mathrm{mL}^{-1}\right)$ in $0.1 \mathrm{M}$ PBS buffer (pH 7.4) prepared by $\mathrm{pH}$-switch post-polymerization method. 
However, the $\mathrm{pH}$-switch method gave mixtures of different morphologies and relatively high PDI values (typically >0.23), rather than one single particle population for all samples (Table 1, entries 5-9). These findings were corroberated by TEM imaging (Fig. 3). The block copolymer with smaller PDPA chain length, P(OEGMA $23-s t$-pFPMA 1$)$ $b$-PDPA 151 , appeared to form micelles (Fig. 3A), while increasing the $\mathrm{DP}_{\mathrm{DPA}}$ to 167 or 187 resulted in worm-like micelles (Fig. 3B and C). The higher DPDPA of 197 appeared to form worm-like aggregates (Fig. 3D) and the highest DPDPA of 235 gave vesicles or spherical aggregates (Fig. 3E).

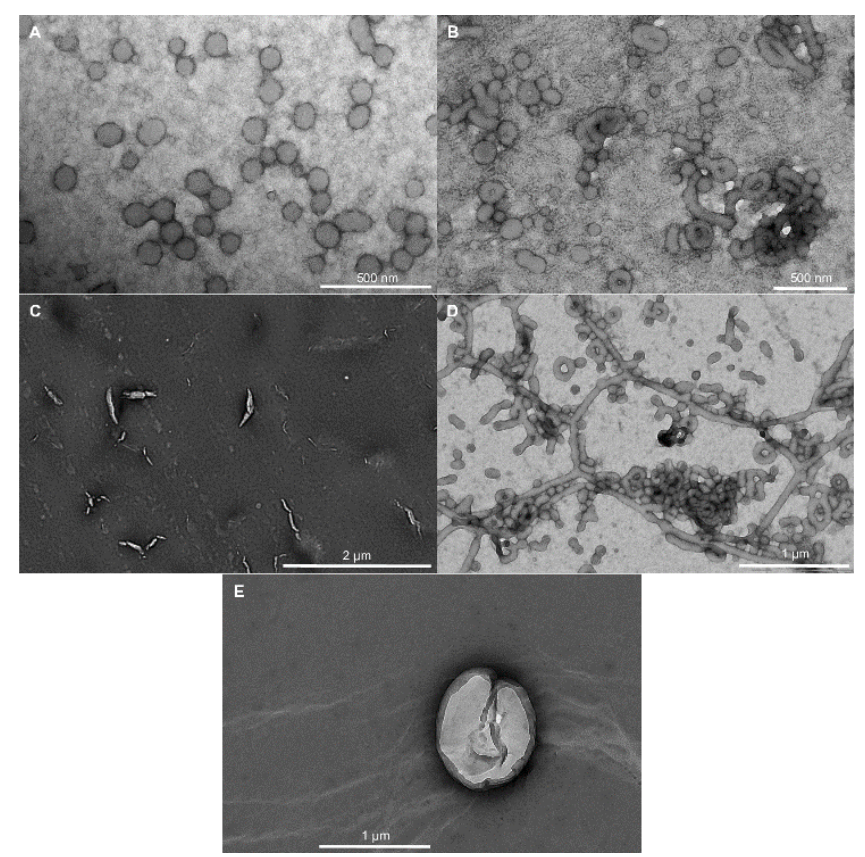

Fig. 3. TEM images of (A) $\mathrm{P}\left(\mathrm{OEGMA}_{23}-s t\right.$-pFPMA 1$)-b$-PDPA 151 , (B) $\mathrm{P}\left(\mathrm{OEGMA}_{23}-s t\right.$ $\left.\mathrm{pFPMA}_{1}\right)-b$-PDPA167, (C) $\mathrm{P}\left(\mathrm{OEGM} \mathrm{A}_{22}-s t\right.$-pFPM $\left.\mathrm{A}_{1}\right)-b$-PDPA186, (D) $\mathrm{P}\left(\mathrm{OEGMA}_{22}-s t\right.$ pFPMA $\left._{1}\right)-b$-PDPA 197 and (E) P(OEGMA $23-s t-$ pFPMA $\left._{1}\right)-b$-PDPA235 amphiphilic diblock copolymer morphologies $\left(5 \mathrm{mg} \mathrm{mL}^{-1}\right)$ in $0.1 \mathrm{M}$ PBS buffer prepared by $\mathrm{pH}$ switch post-polymerization method. Ammonium molybdate was used as the TEM staining agent for all samples.

Encapsulation of Nile Red by $\mathrm{pH}$-switch method using $\mathrm{P}\left(\mathrm{OEGMA}_{22}-\right.$ st-pFPMA 1$)$ $b$-PDPA 197 block copolymer showed that addition of the dye only slightly affected the 
nanoparticle morphology, with DLS data (volume \%) showing only a slight shift to smaller diameters for the encapsulated dye nanoparticle morphologies (Fig. S3).

3.4. Assessment of nanoparticle morphology and dye encapsulation by single emulsion-solvent evaporation method

We have previously reported successful P(OEGMA-st-pFPMA 1 )- $b$-PDPA,[20] PLGA,[29] PLGA-PEG[28,30] nanoparticle formation using single emulsion-solvent evaporation techniques. The same method was applied as an alternative to the $\mathrm{pH}$-switch methodology for producing nanoparticles. The DLS data (Fig. 4) showed that regardless of the PDPA block length, a single distribution was obtained for all $\mathrm{P}\left(\mathrm{OEGMA}_{\mathrm{x}}-s t-\mathrm{pFPMA}_{1}\right)-b-\mathrm{PDPA}_{\mathrm{y}}$ samples.

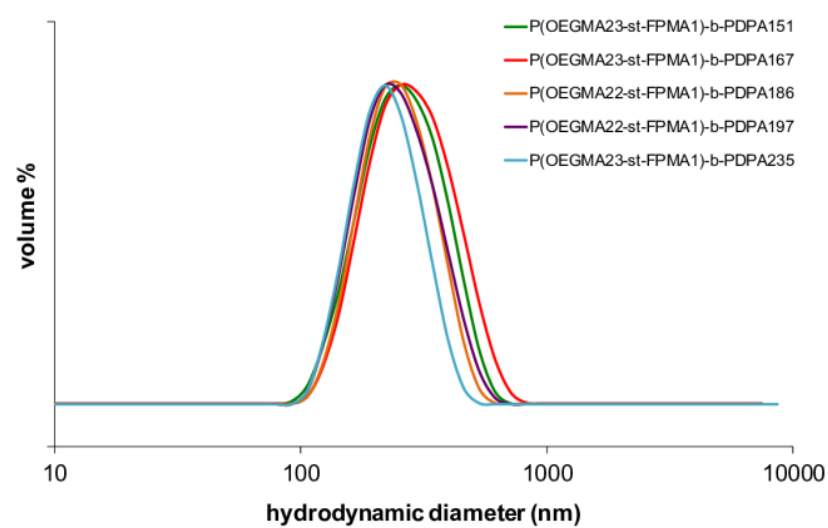

Fig. 4. DLS volume-average diameter distribution of the $\mathrm{P}\left(\mathrm{OEGMA}_{\mathrm{x}}-s t-\mathrm{pFPMA}_{1}\right)-b-\mathrm{PDPA}_{\mathrm{y}}$ amphiphilic block copolymer morphologies $\left(1 \mathrm{mg} \mathrm{mL}^{-1}\right)$ in $0.1 \mathrm{M}$ PBS buffer $(\mathrm{pH} 7.4)$ prepared by single emulsion-solvent evaporation post-polymerization method.

All the samples appeared to have similar mean hydrodynamic diameters in the range of 230 $255 \mathrm{~nm}$ and PDI values were consistently less than 0.14 (Table 1, entries 5-9). SEM imaging of the samples (Fig. 5) confirmed the formation of stable spherical nanoparticles with diameters of approximately $200-300 \mathrm{~nm}$. Encapsulation of rhodamine 6G in P(OEGMA $23-s t$-pFPMA 1 $b$-PDPA 235 by single emulsion-solvent evaporation was not found to affect the nanoparticle morphology. As shown in Fig. S4, the DLS volume weighted diameter distribution is almost 
the same for the $\mathrm{P}\left(\mathrm{OEGMA}_{23}-s t\right.$ - $\left.\mathrm{pFPMA}_{1}\right)-b$-PDPA 235 nanoparticles that do not contain any dye and those loaded with rhodamine 6G. It is worth mentioning here that encapsulation of rhodamine $6 \mathrm{G}$ in the self-assembled nanoparticles (polymer vesicles) prepared by $\mathrm{pH}$-switch was found to break down the vesicle structure, while, as shown above, Nile Red only slightly disturbed their structure. Although the self-assembled P(OEGMA-st-pFPMA)- $b$-PDPA morphologies prepared by $\mathrm{pH}$-switch, such as polymer vesicles, have the advantage of being able to encapsulate hydrophilic molecules (in their core) in addition to hydrophobic ones (in their shell), their structure did not appear to be as robust as the polymeric spheres prepared by single emulsion-solvent evaporation method. Therefore, in the following $\mathrm{pH}$-responsiveness, dye attachment and nanoparticle cell uptake experiments P(OEGMA-st-pFPMA)- $b$-PDPA nanoparticles prepared by single emulsion-solvent evaporation were utilized.

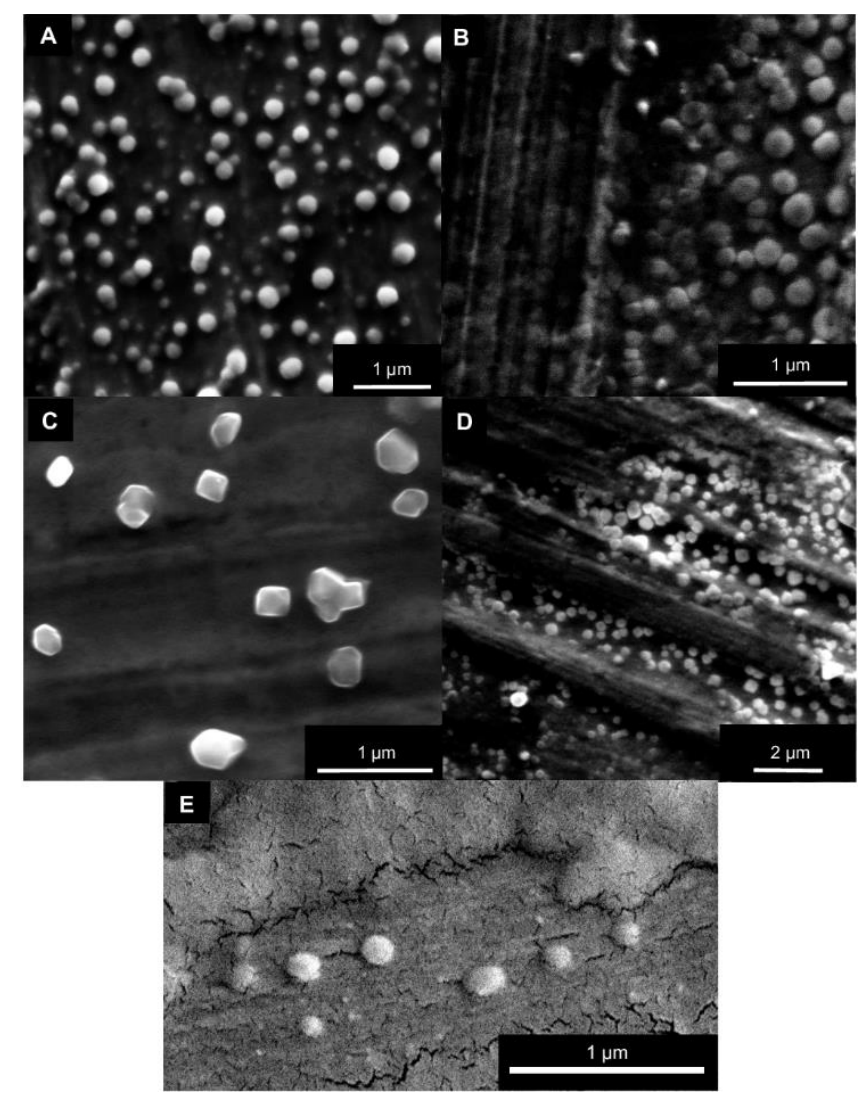

Fig. 5. SEM images of (A) $\mathrm{P}\left(\mathrm{OEGMA}_{23}-s t-\mathrm{pFPMA}_{1}\right)-b-\mathrm{PDPA}_{151}$, (B) $\mathrm{P}\left(\mathrm{OEGMA}_{23}-s t-\right.$ pFPMA $\left._{1}\right)-b$-PDPA 167, (C) $\mathrm{P}\left(\mathrm{OEGMA}_{22}-s t\right.$-pFPMA 1 )- $b$-PDPA 186, (D) $\mathrm{P}\left(\mathrm{OEGMA}_{22}-s t-\right.$ $\left.\mathrm{pFPMA}_{1}\right)-b$-PDPA 197 and (E) $\mathrm{P}\left(\mathrm{OEGMA}_{23}-s t-\mathrm{pFPMA}_{1}\right)-b-\mathrm{PDPA}_{235}$ amphiphilic diblock 
copolymer morphologies $\left(5 \mathrm{mg} \mathrm{mL} \mathrm{mL}^{-1}\right.$ ) in $0.1 \mathrm{M}$ PBS buffer prepared by single emulsionsolvent evaporation post-polymerization method $\left(5 \mathrm{mg} \mathrm{mL}^{-1}\right)$.

\section{5. pH-Responsiveness of P(OEGMA-st-pFMA)-b-PDPA polymeric nanoparticles}

Battaglia et al. [43] reported that PDPA-containing amphiphilic block copolymer nanoparticles can collapse in acidic conditions to release encapsulated payload as PDPA, with a $\mathrm{p} K_{\mathrm{a}}$ value of $\sim 6.4$, is protonated in acidic conditions. Similarly, we have also reported[20] a faster burst release of rhodamine 6G from PDPA-based nanoparticles at $\mathrm{pH} 5.5$ (lower than the $\mathrm{p} K_{\mathrm{a}}$ value of PDPA) compared to $\mathrm{pH} 7.4$ and 6.5 (higher than PDPA $\mathrm{p} K_{\mathrm{a}}$ value). This was attributed to the nanoparticle collapse at the low $\mathrm{pH}$ due to PDPA protonation at low $\mathrm{pH}$. Here, DLS measuments confirmed the loss of nanostructure integrity of P(OEGMA-st-pFPMA)- $b$ PDPA polymer nanoparticles (prepared by single emulsion-solvent evaporation) at low $\mathrm{pH}$ (Fig. 6 and Table S1). More specifically, decreasing the $\mathrm{pH}$ of a P(OEGMA23-st-pFPMA 1$)-b$ PDPA $_{235}$ solution from 7.4 to 4.0 caused a decrease in the size of the nanoparticles from 214 $\mathrm{nm}$ to $121 \mathrm{~nm}$ (Table S1). The reorganization of the polymer chains from larger to smaller nanostructures is likely to induce burst release of encapsulated therapeutics. It is worth

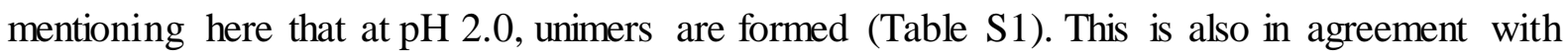
the visual assessment of the pH-switch samples (Fig. S5). Nanoparticles suspended in buffer with $\mathrm{pH}$ value of 7.4 , above the $\mathrm{p} K_{\mathrm{a}}$ value of the PDPA block ( 6.4) [43], appearing turbid, indicative of nanoparticle formation (Fig. S5B). Conversely, lowering the $\mathrm{pH}$ value to 2.0, below the $\mathrm{p} K_{\mathrm{a}}$ value of the PDPA block, resulted in disruption of the nanoparticle structure and eventually, a transparent solution of polymer unimers (Fig. S5A). 


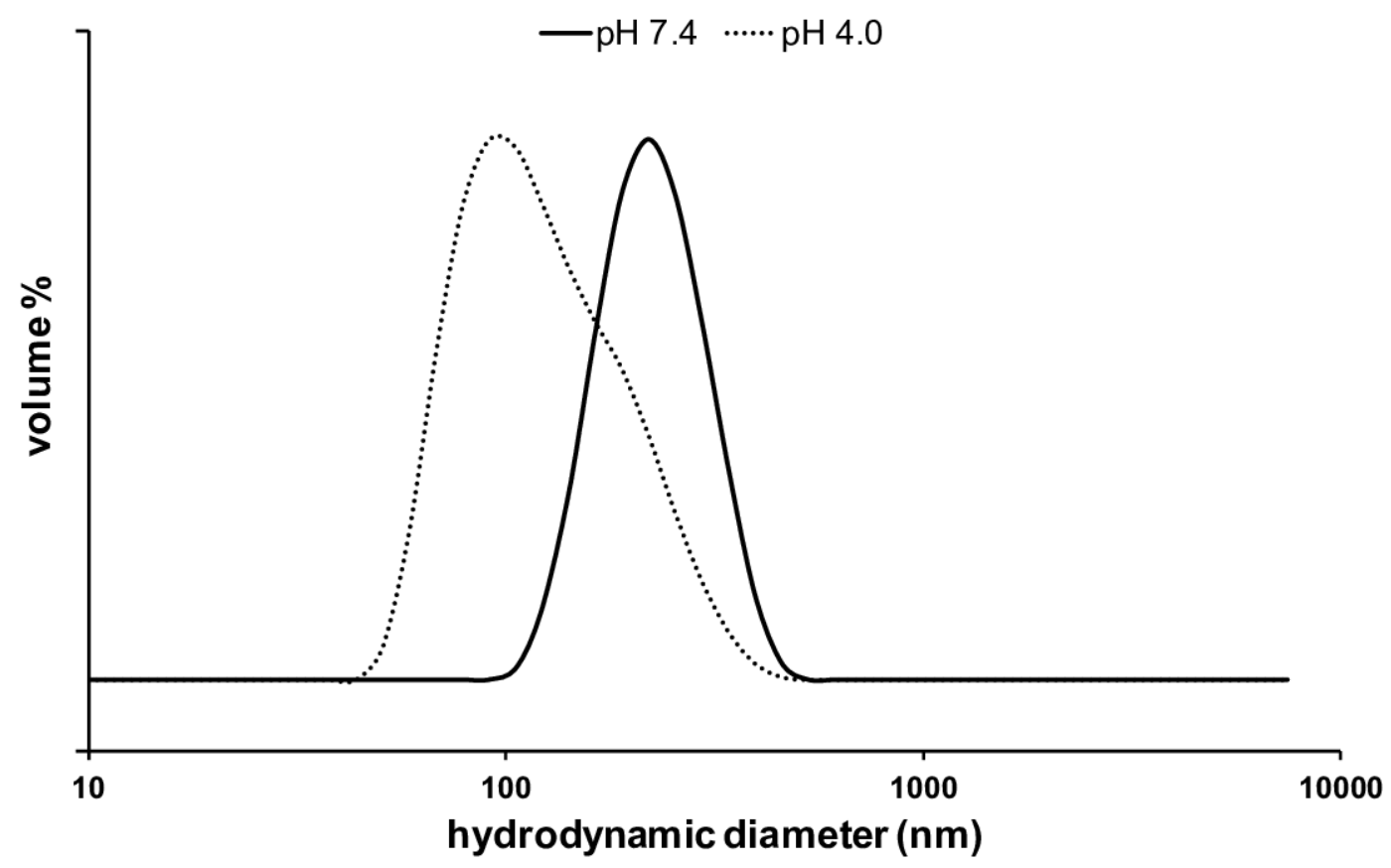

Fig. 6. DLS volume weighted diameter distribution of $\mathrm{P}\left(\mathrm{OEGMA}_{23}-s t-\mathrm{pFPMA}_{1}\right)-b-$ PDPA $_{235}$ amphiphilic block copolymer nanoparticles prepared by single emulsionsolvent evaporation in PBS buffer $\left(2 \mathrm{mg} \mathrm{mL}^{-1}\right)$ at different solution $\mathrm{pH}$ values. PBS buffer at $\mathrm{pH} 7.4$ was used as a control.

3.6. In vitro cytotoxicity of amphiphilic block copolymer morphologies

In addition to assessing the physical characteristics of the polymer nanoparticle formulations, it was vital to ensure that they would cause no significant cytotoxicity. For assessing the nanoparticle biocompatibility, $\quad$ (OEGMA $22-s t-$ pFPMA $\left._{1}\right)-b-\mathrm{PDPA}_{197}$ nanoparticles (0-0.2 $\left.\mathrm{mg} \mathrm{mL}^{-1}\right)$ prepared by $\mathrm{pH}$-switch method were incubated with HCT116 cells for $48 \mathrm{~h}$ before cell viability was assessed via MTT assay. At the concentrations evaluated, the nanoparticles produced no significant alterations in cell viability, indicating that the particles were well tolerated (Fig. 7). 


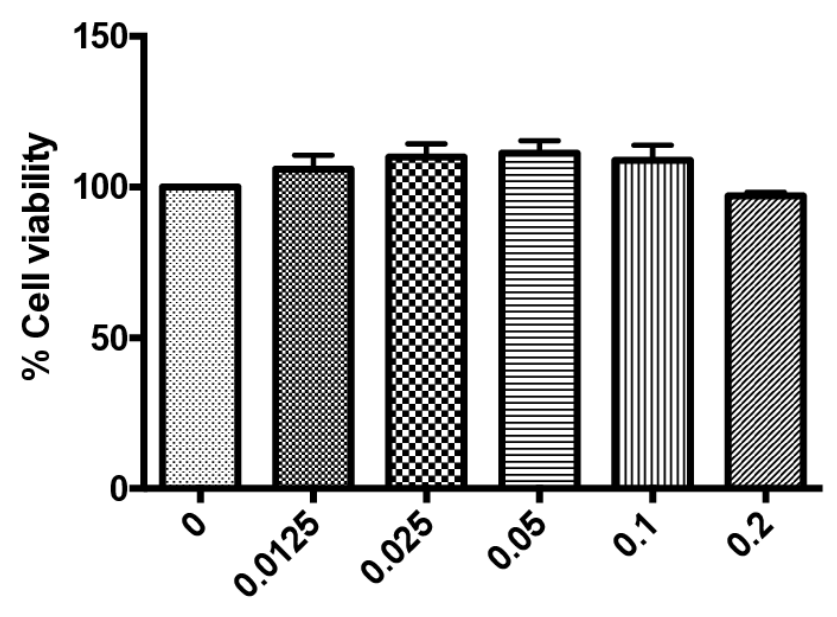

Polymer $(\mathrm{mg} / \mathrm{ml})$

Fig. 7. Assessment of intrinsic formulation toxicity. HCT116 cells were treated with varying concentrations $\left(c=0.0125,0.025,0.05,0.1\right.$ and $\left.0.2 \mathrm{mg} \mathrm{mL}^{-1}\right)$ of benzaldehyde-functionalized $\mathrm{P}\left(\mathrm{OEGMA}_{23} \text {-st-pFPMA }\right)_{1}$ - $b$-PDPA 197 polymeric nanoparticle morphologies prepared by $\mathrm{pH}$ switch method for $48 \mathrm{~h}$ and assessed in terms of cell viability by MTT assay. PBS buffer was used as a negative control $\left(c=0 \mathrm{mg} \mathrm{mL}^{-1}\right)$.

\subsection{Conjugation of Alexa Fluor ${ }^{T M} 488$ hydroxylamine dye to P(OEGMA-st-pFPMA)-b-PDPA}

polymeric nanoparticles

In order to assess the reactivity of the pFPMA benzaldehyde groups on the nanoparticle exterior and, more specifically, their ability to react with molecules containing aminooxy groups to form oxime bonds, an Alexa Fluor ${ }^{\mathrm{TM}} 488$ hydroxylamine dye was used. This conjugation approach was deemed particularly suitable as the conjugates formed, via carbonnitrogen double bonds, are notably robust against hydrolysis [44]. To improve the conjugation efficiency, $p$-PDA was chosen as the catalyst to be used for this reaction. Whilst aniline has classically been utilised to catalyze oxime and hydrazone ligations, meta- and paraphenylenediamines have been shown to facilitate this at much faster rates [45]. Following conjugation, nanoparticles were washed with PBS buffer and the conjugation was assessed by fluorescence (Fig. 8A). It was noted that fluorescent signal was solely evidenced in the presence of the Alexa Fluor ${ }^{\mathrm{TM}} 488$ hydroxylamine dye. Additionally, the necessity of the catalyst to provide enhanced levels of conjugation indicates that the hydroxylamine compound 
is chemically conjugated via an oxime linkage to the nanoparticles, facilitated by the presence of $p$-PDA. As an added control, Alexa Fluor ${ }^{\mathrm{TM}} 488$ hydroxylamine dye in the absence of $\mathrm{P}(\mathrm{OEGMA}-s t$-pFPMA)- $b$-PDPA nanopartic les was put through the same conjugation process. The lack of signal from these controls illustrates that fluorescence is the result of conjugation to the nanoparticles, not merely aggregation of the hydroxylamine dye. SEC (THF) data (Fig. S6) showed that conjugation of the dye to the $\mathrm{P}\left(\mathrm{OEGMA}_{23}-s t-\mathrm{pFPMA}_{1}\right)-b-\mathrm{PDPA}_{186}$ amphiphilic block copolymer nanoparticle resulted in a shift of the maximum peak of the SEC chromatogram to lower elution times indicative of higher molecular weights. For the two different concentrations of dye used for conjugation, the higher concentration $(3 \% \mathrm{w} / \mathrm{w})$ gave a higher molecular weight $\left(M_{\mathrm{n}}=44,300 \mathrm{~g} \mathrm{~mol}^{-1}\right)$ than the lower concentration $(1 \% \mathrm{w} / \mathrm{w})$ used $\left(M_{\mathrm{n}}=36,100 \mathrm{~g} \mathrm{~mol}^{-1}\right)$, while both concentrations gave higher $M_{\mathrm{n}}$ values than the initial nonconjugated $\mathrm{P}\left(\mathrm{OEGMA}_{23}-s t\right.$-pFPMA 1$)-b$-PDPA 186 polymer sample $\left(M_{\mathrm{n}}=44,300 \mathrm{~g} \mathrm{~mol}^{-1}\right)$, suggesting that the attachment of the dye to the polymer nanoparticles was successful. Assessment of nanoparticle size following Alexa Fluor ${ }^{\mathrm{TM}} 488$ hydroxylamine attachment, as determined by DLS, showed that nanoparticle physical characteristics were not greatly altered, illustrating further the suitability of this approach (Fig. 8B and Fig. S7). 


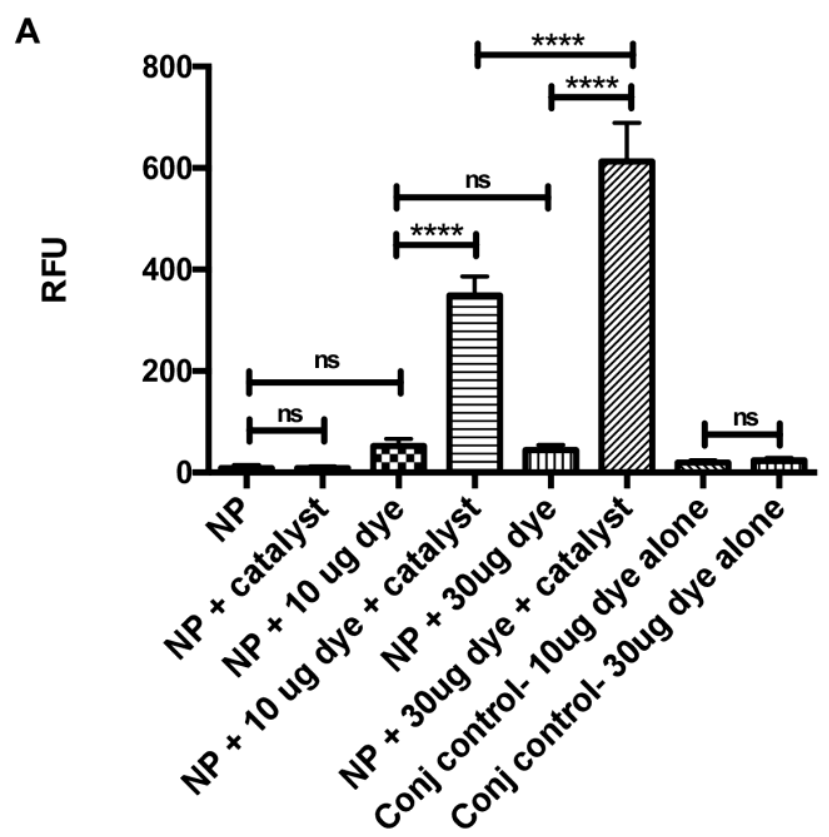

B

\begin{tabular}{|c|c|c|}
\hline Formulation & Diameter $(\mathrm{nm})$ & Polydispersity \\
\hline Nude Nanoparticle & $264.36 \pm 4.31$ & $0.110 \pm 0.005$ \\
\hline $\begin{array}{c}\text { Nanoparticle + 10ug dye } \\
\text { + catalyst }\end{array}$ & $265.41 \pm 2.31$ & $0.067 \pm 0.032$ \\
\hline
\end{tabular}

Fig. 8. Assessment of Alexa Fluor ${ }^{\mathrm{TM}} 488$ hydroxylamine dye conjugation to P(OEGMA-stpFPMA)- $b$-PDPA polymer nanoparticles. Alexa Fluor ${ }^{\mathrm{TM}} 488$ hydroxylamine dye was attached to $\mathrm{P}\left(\mathrm{OEGMA}_{23}-s t\right.$-pFPMA 1 - $b$-PDPA186 nanoparticles in the presence of paraphenylenediamine ( $p$-PDA) catalyst. Nanoparticles were subsequently assessed in terms of (A) conjugation via fluorescence measured at ex $488 \mathrm{~nm} / \mathrm{em} 518 \mathrm{~nm}$ and (B) physical characteristics (hydrodynamic diameter size) as determined by DLS.

\subsection{In vitro nanoparticle uptake}

In order to demonstrate the ability of the nanoparticles to deliver a payload to cells, rhodamine 6G was encapsulated within nanoparticles as a surrogate drug entity. Following formulation via the single emulsion-solvent evaporation approach the fluorescent nanoparticles were incubated with both A2780 ovarian cancer and A549 lung epithelial human cells in vitro. Following the $2 \mathrm{~h}$ treatment period, cells were washed and fixed, prior to assessment via confocal microscopy. Visual assessment illustrated that the rhodamine 6G loaded nanopartic les had been successfully internalised in both cell lines (Fig. 9). This further highlights the 
potential for these formulations to be used as vehicles for triggered release therapeutic drug delivery applications.

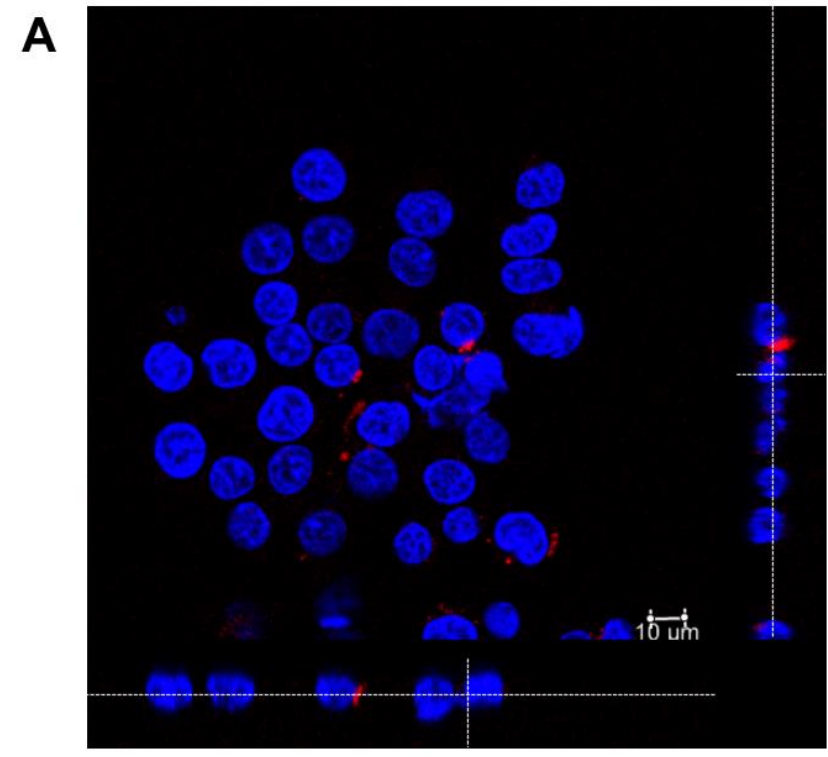

B

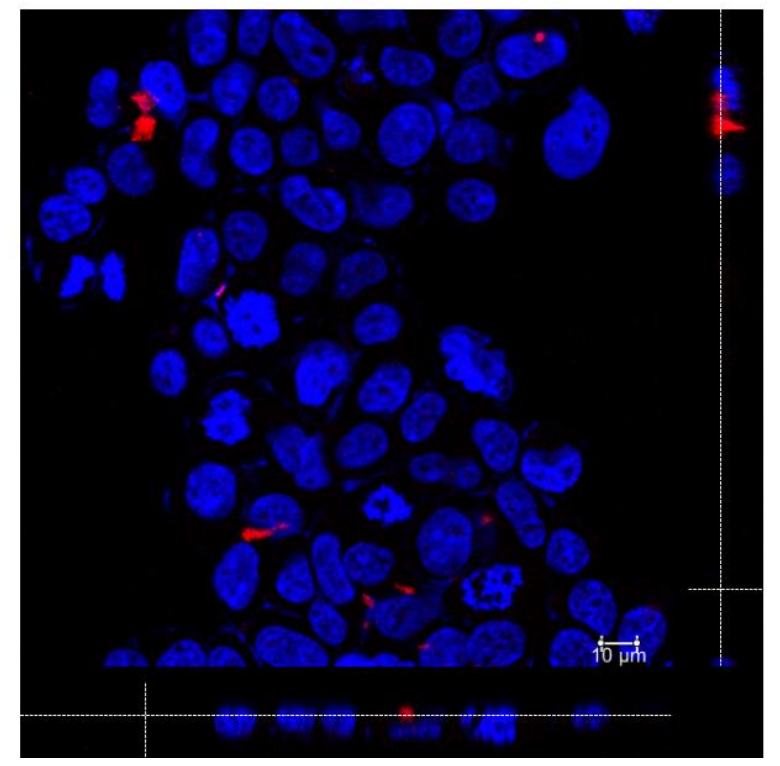

Fig. 9. Assessment of $\mathrm{P}\left(\mathrm{OEGMA}_{23}-s t\right.$-pFPMA 1$)-b$ - $\mathrm{PDPA}_{235}$ nanoparticle uptake in $\mathrm{A} 2780$ and A549 cells. (A) A2780 and (B) A549 cells were both treated with rhodamine 6G loaded $\mathrm{P}\left(\mathrm{OEGMA}_{23}-s t\right.$-pFPMA 1$)-b$-PDPA 235 nanoparticles prepared via single emulsion-solvent evaporation. Following treatment the cells were washed, fixed and nuclear regions were stained with DAPI. Cells were subsequently imaged by confocal microscopy. Scale bars $=10 \mu \mathrm{m}$. 


\section{Conclusions}

The development of nanosized therapeutic systems based on novel benzaldehyde functionalized pH-responsive PEGylated nanoparticles has great potential in the biomedical field, and especially in diagnostics and drug delivery. For example, attachment of aminooxyfunctionalized fluorescent dyes by oxime bond formation with the benzaldehyde groups on the nanoparticle surface can give dye-functionalized nanoparticles that can be used in diagnostic applications. Also, attachment of an antibody to these nanoparticles by reaction with the benzaldehyde groups on their surface can be potentially used for cancer treatment, since they can target therapeutic agents at disease sites. Here, we have demonstrated the preparation of a series of benzaldehyde-functionalized P(OEGMA-st-pFPMA)- $b$-PDPA amphiphilic block copolymers by RAFT polymerization in biologically compatible solvents. Amphiphilic block copolymers and their macro-CTAs were prepared with high monomer \% conversions, reasonable polymerization times and good control. P(OEGMA-st-pFPMA)- $b$-PDPA polymeric nanostructures were prepared using two methods; $\mathrm{pH}$-switch and single emulsion-solvent evaporation. It was found that increasing the block length of the PDPA hydrophobic (in neutral $\mathrm{pH}$ ) block had a significant effect on the size and morphology of the nanostructures formed by the $\mathrm{pH}$-switch method, as evaluated by DLS and TEM. For the single emulsion-solvent evaporation method however, the length of the PDPA block showed little effect on the size and morphology of the resulting nanostructures. These nanoparticles contain a biocompatible and benzaldehyde-functionalized hydrophilic surface that endows them with 'stealth' properties and the potential for functionalization with biologically important molecules for drug delivery and diagnostic applications. The P(OEGMA-st-pFPMA)- $b$-PDPA polymer nanoparticles prepared by both methods were shown to be $\mathrm{pH}$-responsive, with collapse of their nanostructures being observed at $\mathrm{pH}$ values lower than 6.4 ( $\mathrm{p} K_{\mathrm{a}}$ value of PDPA block). Fluorescent dye encapsulation was found to slightly affect the morphology of the pH-switch 
self-assembled nanoparticles, giving lower hydrodynamic diameter values by DLS. Encapsulation by single emulsion-solvent evaporation did not affect the diameter distribution of the nanoparticles. The pH-responsiveness of these nanoparticles has the potential to be used for triggered release of encapsulated cargo. Furthermore, it was shown that through the incorporation of a reactive benzaldehyde group in the hydrophilic block of the amphiphilic block copolymer, chemical conjugation of targeting moieties to the nanoparticle surface was possible. This was illustrated through the conjugation of a fluorescent dye, possessing a reactive aminooxy group, to the nanoparticle via the formation of a stable oxime bond. This added functionality opens up the possibility of actively targeting the nanoparticles to specific sites and/or cell types, in turn maximizing the efficacy of drug therapy whilst minimizing off target effects. Alternatively, such active targeting has the potential to be of use in a diagnostic setting, with, for instance, the nanoparticles accumulating at the desired site for imaging. Using rhodamine $6 \mathrm{G}$ as a surrogate drug entity, the successful delivery of an encapsulated cargo was demonstrated, in vitro, in different cell lines, highlighting the potential for using these nanoformulations as drug delivery vehicles in a therapeutic setting.

\section{Acknowledgements}

The authors acknowledge the Engineering and Physical Sciences Research Council (EPSRC) (S3802ASA) and the Department for the Economy (DfE) for funding of the Ph.D. studentships of P.S. and T.J.G, respectively. This work was also partially funded through a US-Ireland R\&D Partnership grant awarded by HSCNI (STL/5010/14).

\section{Appendix A. Supplementary material}


Supplementary data to this article can be found online at https://doi.org/10.1016/j.eurpolymj.xxxx.xx.xxx.

\section{References}

[1] J. Chiefari, Y.K. (Bill) Chong, F. Ercole, J. Krstina, J. Jeffery, T.P.T. Le, R.T.A. Mayadunne, G.F. Meijs, C.L. Moad, G. Moad, E. Rizzardo, S.H. Thang, Living FreeRadical Polymerization by Reversible Addition-Fragmentation Chain Transfer: The RAFT Process, Macromolecules. 31 (1998) 5559-5562. doi:10.1021/ma9804951.

[2] G. Moad, E. Rizzardo, S.H. Thang, Living Radical Polymerization by the RAFT Process? A Third Update, Aust. J. Chem. 65 (2012) 985-1076. doi:10.1071/CH12295.

[3] G. Moad, E. Rizzardo, S.H. Thang, Living Radical Polymerization by the RAFT Process, Aust. J. Chem. 58 (2005) 379-410. doi:10.1071/CH05072.

[4] R.T.A. Mayadunne, E. Rizzardo, J. Chiefari, Y.K. Chong, G. Moad, S.H. Thang, Living Radical Polymerization with Reversible Addition-Fragmentation Chain Transfer (RAFT Polymerization) Using Dithiocarbamates as Chain Transfer Agents, Macromolecules. 32 (1999) 6977-6980. doi:10.1021/ma9906837.

[5] A. Blanazs, S.P. Armes, A.J. Ryan, Self-Assembled Block Copolymer Aggregates: From Micelles to Vesicles and their Biological Applications, Macromol. Rapid Commun. 30 (2009) 267-277. doi:10.1002/marc.200800713.

[6] N.J. Warren, S.P. Armes, Polymerization-Induced Self-Assembly of Block Copolymer Nano-objects via RAFT Aqueous Dispersion Polymerization, J. Am. Chem. Soc. 136 (2014) 10174-10185. doi:10.1021/ja502843f.

[7] L. Zhang, A. Eisenberg, Morphogenic Effect of Added Ions on Crew-Cut Aggregates of Polystyrene- $b$-poly(acrylic acid) Block Copolymers in Solutions, Macromolecules. 29 (1996) 8805-8815. doi:10.1021/ma961376t. 
[8] C. LoPresti, H. Lomas, M. Massignani, T. Smart, G. Battaglia, Polymersomes: nature inspired nanometer sized compartments, J. Mater. Chem. 19 (2009) 3576-3590. doi:10.1039/b818869f.

[9] F.S. Bates, G.H. Fredrickson, Block Copolymers-Designer Soft Materials, Phys. Today. 52 (1999) 32-38. doi:10.1063/1.882522.

[10] L. Zhang, A. Eisenberg, Multiple Morphologies of \&quot;Crew-Cut\&quot; Aggregates of Polystyrene-b-poly(acrylic acid) Block Copolymers, Science (80-. ). 268 (1995) 1728-1731. doi:10.1126/science.268.5218.1728.

[11] K. Knop, R. Hoogenboom, D. Fischer, U.S. Schubert, Poly(ethylene glycol) in Drug Delivery: Pros and Cons as Well as Potential Alternatives, Angew. Chemie Int. Ed. 49 (2010) 6288-6308. doi:10.1002/anie.200902672.

[12] E. Kaditi, G. Mountrichas, S. Pispas, Amphiphilic block copolymers by a combination of anionic polymerization and selective post-polymerization functionalization, Eur. Polym. J. 47 (2011) 415-434. doi:10.1016/j.eurpolymj.2010.09.012.

[13] F.M. Veronese, O. Schiavon, G. Pasut, R. Mendichi, L. Andersson, A. Tsirk, J. Ford, G. Wu, S. Kneller, J. Davies, R. Duncan, PEG-Doxorubicin Conjugates: Influence of Polymer Structure on Drug Release, in Vitro Cytotoxicity, Biodistribution, and Antitumor Activity, Bioconjug. Chem. 16 (2005) 775-784. doi:10.1021/bc040241m.

[14] G. Mantovani, V. Ladmiral, L. Tao, D.M. Haddleton, One-pot tandem living radical polymerisation-Huisgens cycloaddition process (“click”) catalysed by N-alkyl-2pyridylmethanimine/Cu(i)Br complexes, Chem. Commun. (2005) 2089-2091. doi:10.1039/B500558B.

[15] J. Madsen, I. Canton, N.J. Warren, E. Themistou, A. Blanazs, B. Ustbas, X. Tian, R. Pearson, G. Battaglia, A.L. Lewis, S.P. Armes, Nile Blue-Based Nanosized pH Sensors for Simultaneous Far-Red and Near-Infrared Live Bioimaging, J. Am. Chem. 
Soc. 135 (2013) 14863-14870. doi:10.1021/ja407380t.

[16] J. Madsen, G. Madden, E. Themistou, N.J. Warren, S.P. Armes, pH-Responsive diblock copolymers with two different fluorescent labels for simultaneous monitoring of micellar self-assembly and degree of protonation, Polym. Chem. 9 (2018) 29642976. doi:10.1039/C8PY00111A.

[17] A. Petropoulou, T.J. Gibson, E. Themistou, S. Pispas, C. Riziotis, Development of amphiphilic block copolymers as silica optical fiber overlayers for BSA protein detection, Mater. Chem. Phys. 216 (2018) 421-428. doi:10.1016/j.matchemphys.2018.06.027.

[18] P. Thordarson, B. Le Droumaguet, K. Velonia, Well-defined protein-polymer conjugates-synthesis and potential applications, Appl. Microbiol. Biotechnol. 73 (2006) 243-254. doi:10.1007/s00253-006-0574-4.

[19] D. Bontempo, H.D. Maynard, Streptavidin as a macroinitiator for polymerization: in situ protein-polymer conjugate formation., J. Am. Chem. Soc. 127 (2005) 6508-6509. doi:10.1021/ja042230+.

[20] T.J. Gibson, P. Smyth, W.J. McDaid, D. Lavery, J. Thom, G. Cotton, C.J. Scott, E. Themistou, Single-Domain Antibody-Functionalized pH-Responsive Amphiphilic Block Copolymer Nanoparticles for Epidermal Growth Factor Receptor Targeted Cancer Therapy, ACS Macro Lett. 7 (2018) 1010-1015. doi:10.1021/acsmacrolett.8b00461.

[21] Z. Luo, Y. Xu, E. Ye, Z. Li, Y.-L. Wu, Recent Progress in Macromolecule-Anchored Hybrid Gold Nanomaterials for Biomedical Applications, Macromol. Rapid Commun. 40 (2019) 1800029. doi:10.1002/marc.201800029.

[22] L. Ruiz-Pérez, J. Madsen, E. Themistou, J. Gaitzsch, L. Messager, S.P. Armes, G. Battaglia, Nanoscale detection of metal-labeled copolymers in patchy polymersomes, 
Polym. Chem. 6 (2015) 2065-2068. doi:10.1039/C4PY01508H.

[23] A. El Sachat, A. Meristoudi, S. Pispas, C. Riziotis, Assessment of block and random copolymer overlayers on polymer optical fibers toward protein detection through electrostatic interaction, J. Polym. Sci. Part B Polym. Phys. 53 (2015) 327-334. doi:10.1002/polb.23632.

[24] J. Cheng, B. Teply, I. Sherifi, J. Sung, G. Luther, F. Gu, E. Levynissenbaum, A. Radovicmoreno, R. Langer, O. Farokhzad, Formulation of functionalized PLGA-PEG nanoparticles for in vivo targeted drug delivery, Biomaterials. 28 (2007) 869-876. doi:10.1016/j.biomaterials.2006.09.047.

[25] J. Mao, Y. Li, T. Wu, C. Yuan, B. Zeng, Y. Xu, L. Dai, A Simple Dual-pH Responsive Prodrug-Based Polymeric Micelles for Drug Delivery, ACS Appl. Mater. Interfaces. 8 (2016) 17109-17117. doi:10.1021/acsami.6b04247.

[26] G. Sun, H. Fang, C. Cheng, P. Lu, K. Zhang, A. V. Walker, J.-S.A. Taylor, K.L. Wooley, Benzaldehyde-Functionalized Polymer Vesicles, ACS Nano. 3 (2009) 673681. doi:10.1021/nn8007977.

[27] H. Lomas, I. Canton, S. MacNeil, J. Du, S.P. Armes, A.J. Ryan, A.L. Lewis, G. Battaglia, Biomimetic pH Sensitive Polymersomes for Efficient DNA Encapsulation and Delivery, Adv. Mater. 19 (2007) 4238-4243. doi:10.1002/adma.200700941.

[28] D. Schmid, F. Fay, D.M. Small, J. Jaworski, J.S. Riley, D. Tegazzini, C. Fenning, D.S. Jones, P.G. Johnston, D.B. Longley, C.J. Scott, Efficient Drug Delivery and Induction of Apoptosis in Colorectal Tumors Using a Death Receptor 5-Targeted Nanomedicine, Mol. Ther. 22 (2014) 2083-2092. doi:10.1038/mt.2014.137.

[29] S. Spence, M.K. Greene, F. Fay, E. Hams, S.P. Saunders, U. Hamid, M. Fitzgerald, J. Beck, B.K. Bains, P. Smyth, E. Themistou, D.M. Small, D. Schmid, C.M. O'Kane, D.C. Fitzgerald, S.M. Abdelghany, J.A. Johnston, P.G. Fallon, J.F. Burrows, D.F. 
McAuley, A. Kissenpfennig, C.J. Scott, Targeting Siglecs with a sialic acid-decorated nanoparticle abrogates inflammation, Sci. Transl. Med. 7 (2015) 303ra140. doi:10.1126/scitranslmed.aab3459.

[30] D. Schmid, G.E. Jarvis, F. Fay, D.M. Small, M.K. Greene, J. Majkut, S. Spence, K.M. McLaughlin, K.D. McCloskey, P.G. Johnston, A. Kissenpfennig, D.B. Longley, C.J. Scott, Nanoencapsulation of ABT-737 and camptothecin enhances their clinical potential through synergistic antitumor effects and reduction of systemic toxicity, Cell Death Dis. 5 (2014) e1454. doi:10.1038/cddis.2014.413.

[31] M. Wendeler, L. Grinberg, X. Wang, P.E. Dawson, M. Baca, Enhanced Catalysis of Oxime-Based Bioconjugations by Substituted Anilines, Bioconjug. Chem. 25 (2014) 93-101. doi:10.1021/bc400380f.

[32] A. Blanazs, M. Massignani, G. Battaglia, S.P. Armes, A.J. Ryan, Tailoring Macromolecular Expression at Polymersome Surfaces, Adv. Funct. Mater. 19 (2009) 2906-2914. doi:10.1002/adfm.200900201.

[33] B. García-Acosta, F. García, J.M. García, R. Martínez-Máñez, F. Sancenón, N. SanJosé, J. Soto, Chromogenic Signaling of Hydrogen Carbonate Anion with PyryliumContaining Polymers, Org. Lett. 9 (2007) 2429-2432. doi:10.1021/o10705191.

[34] D. Prat, A. Wells, J. Hayler, H. Sneddon, C.R. McElroy, S. Abou-Shehada, P.J. Dunn, CHEM21 selection guide of classical- and less classical-solvents, Green Chem. 18 (2016) 288-296. doi:10.1039/C5GC01008J.

[35] Y.-P. Li, Y.-Y. Pei, X.-Y. Zhang, Z.-H. Gu, Z.-H. Zhou, W.-F. Yuan, J.-J. Zhou, J.-H. Zhu, X.-J. Gao, PEGylated PLGA nanoparticles as protein carriers: synthesis, preparation and biodistribution in rats, J. Control. Release. 71 (2001) 203-211. doi:10.1016/S0168-3659(01)00218-8.

[36] C.D. Walkey, J.B. Olsen, H. Guo, A. Emili, W.C.W. Chan, Nanoparticle Size and 
Surface Chemistry Determine Serum Protein Adsorption and Macrophage Uptake, J. Am. Chem. Soc. 134 (2012) 2139-2147. doi:10.1021/ja2084338.

[37] K. Liang, G.K. Such, A.P.R. Johnston, Z. Zhu, H. Ejima, J.J. Richardson, J. Cui, F. Caruso, Endocytic pH-Triggered Degradation of Nanoengineered Multilayer Capsules, Adv. Mater. 26 (2014) 1901-1905. doi:10.1002/adma.201305144.

[38] J. Clayden, N. Greeves, S. Warren, Organic Chemistry, second ed., Oxford University Press, Oxford, 2012.

[39] L. Zhang, A. Eisenberg, Thermodynamic vs Kinetic Aspects in the Formation and Morphological Transitions of Crew-Cut Aggregates Produced by Self-Assembly of Polystyrene- $b$-poly(acrylic acid) Block Copolymers in Dilute Solution, Macromolecules. 32 (1999) 2239-2249. doi:10.1021/ma981039f.

[40] R. Verber, A. Blanazs, S.P. Armes, Rheological studies of thermo-responsive diblock copolymer worm gels, Soft Matter. 8 (2012) 9915-9922. doi:10.1039/c2sm26156a.

[41] J. Massey, K.N. Power, I. Manners, M.A. Winnik, Self-Assembly of a Novel Organometallic-Inorganic Block Copolymer in Solution and the Solid State: Nonintrusive Observation of Novel Wormlike Poly(ferrocenyldimethylsilane)$b$-Poly(dimethylsiloxane) Micelles, J. Am. Chem. Soc. 120 (1998) 9533-9540. doi:10.1021/ja981803d.

[42] B.M. Discher, Y.-Y. Won, D.S. Ege, J.C.-M. Lee, F.S. Bates, D.E. Discher, D.A. Hammer, Polymersomes: Tough Vesicles Made from Diblock Copolymers, Science (80-. ). 284 (1999) 1143-1146. doi:10.1126/science.284.5417.1143.

[43] M. Massignani, I. Canton, T. Sun, V. Hearnden, S. MacNeil, A. Blanazs, S.P. Armes, A. Lewis, G. Battaglia, Enhanced Fluorescence Imaging of Live Cells by Effective Cytosolic Delivery of Probes, PLoS One. 5 (2010) e10459. doi:10.1371/journal.pone.0010459. 
[44] J. Kalia, R.T. Raines, Hydrolytic Stability of Hydrazones and Oximes, Angew. Chemie Int. Ed. 47 (2008) 7523-7526. doi:10.1002/anie.200802651.

[45] M.M. Mahmoodi, M. Rashidian, Y. Zhang, M.D. Distefano, Application of meta- and para-Phenylenediamine as Enhanced Oxime Ligation Catalysts for Protein Labeling, PEGylation, Immobilization, and Release., Curr. Protoc. Protein Sci. 79 (2015) 15.4.128. doi:10.1002/0471140864.ps1504s79. 